\title{
Performance Assessment of W-Band Radiometers: Direct versus Heterodyne Detections
}

\author{
Juan Pablo Pascual ${ }^{1, *(\mathbb{C}}$, Beatriz Aja ${ }^{1}\left(\mathbb{C}\right.$, Enrique Villa ${ }^{2}{ }^{(\mathbb{C}}$, Jose Vicente Terán ${ }^{3}$, Luisa de la Fuente ${ }^{1}$ \\ and Eduardo Artal ${ }^{1}$ (D) \\ 1 Departamento de Ingeniería de Comunicaciones, Universidad de Cantabria, Plaza de la Ciencia s/n, \\ 39005 Santander, Spain; beatriz.aja@unican.es (B.A.); fuenterm@unican.es (L.d.1.F.); artale@unican.es (E.A.) \\ 2 IACTEC, Instituto de Astrofísica de Canarias, 38205 La Laguna, Spain; evilla@iac.es \\ 3 ERZIA Technologies, 39012 Santander, Spain; vicente.teran@erzia.com \\ * Correspondence: pascualp@unican.es
}

Citation: Pascual, J.P.; Aja, B.; Villa, E.; Terán, J.V.; de la Fuente, L.; Artal, E. Performance Assessment of W-Band Radiometers: Direct versus Heterodyne Detections. Electronics 2021, 10, 2317. https://doi.org/ 10.3390 /electronics10182317

Academic Editors: Giovanni Andrea Casula and Reza K. Amineh

Received: 22 July 2021

Accepted: 18 September 2021

Published: 21 September 2021

Publisher's Note: MDPI stays neutral with regard to jurisdictional claims in published maps and institutional affiliations.

Copyright: (c) 2021 by the authors. Licensee MDPI, Basel, Switzerland. This article is an open access article distributed under the terms and conditions of the Creative Commons Attribution (CC BY) license (https:// creativecommons.org/licenses/by/ $4.0 /)$.
Abstract: W-Band radiometers using intermediate frequency down-conversion (super-heterodyne) and direct detection are compared. Both receivers consist of two W-band low noise amplifiers and an 80 -to-101 GHz filter, which conforms to the reception frequency band, in the front-end module. The back-end module of the first receiver comprises a subharmonic mixer, intermediate frequency (IF) amplification and a square-law detector. For direct detection, a W-Band detector replaces the mixer and the intermediate frequency detection stages. The performance of the whole receivers has been simulated requiring special techniques, based on data from the experimental characterization of each subsystem. In the super-heterodyne implementation a local oscillator at $27.1 \mathrm{GHz}$ (with $8 \mathrm{dBm}$ ) with a $x 3$ frequency multiplier is used, exhibiting an overall conversion gain around $48 \mathrm{~dB}$, a noise figure around $4 \mathrm{~dB}$, and an effective bandwidth over $10 \mathrm{GHz}$. In the direct detection scheme, slightly better noise performance is obtained, with a wider bandwidth, around $20 \mathrm{GHz}$, since there is no IF bandwidth limitation ( $15 \mathrm{GHz})$, and even using the same 80 -to-101 GHz filter, the detector can operate through the whole W-band. Moreover, W-band detector has higher sensitivity than the IF detector, increasing slightly the gain. In both cases, the receiver performance is characterized when a broadband noise input signal is applied. The radiometer characteristics have been obtained working as a total power radiometer and as a Dicke radiometer when an optical chopper is used to modulate the incoming signal. Combining this particular super-heterodyne or direct detection topologies and total power or Dicke modes of operation, four different cases are compared and discussed, achieving similar sensitivities, but better performances in terms of equivalent bandwidth and noise for the direct detection radiometer. It should be noted that this conclusion comes from a particular set of components, which we could consider as typical, but we cannot exclude other conclusions for different components, particularly for different mixers and detectors.

Keywords: radiometers; detectors; W-band

\section{Introduction}

In $\mathrm{W}$-band, there are two main areas of interest for radiometric systems: one of them features scientific applications that include observations of the Earth, radio astronomy [1,2] and spectroscopy [3]; the other one includes the security control applications and low visibility situations through the acquisition of millimeter wave images [4,5]. Among the experiments in the field of radio astronomy are those devoted to analyzing the Cosmic Microwave Background (CMB), which are affected by undesired signals such as foreground emission [6]. The W-band (75-110 GHz) offers an atmospheric window for terrestrial observation of CMB. The very low noise receivers used in radio astronomy are radiometers that require high stability and sensitivity and allow to measure the electromagnetic emission of a body, distinguishing small levels of signal power [7-9]. The sensitivity of the radiometer is established by the temperature of the lowest detectable source, which is generally 
bounded by the noise fluctuations that appear at the output of the receiver for a null input. For a thermal noise type signal, special techniques are used in order to reduce the fluctuations of noise and gain produced by the circuits of the receiver itself and to be able to distinguish them from the signal of interest to be measured.

A total power radiometer provides an average value of the voltage given by a quadratic-law diode detector, proportional to the noise power received by the antenna plus the receiver. The radiometric sensitivity, defined as the minimum detectable temperature change of the antenna expressed in Kelvin, at the radiometer output depends on the system thermal noise $\mathrm{T}_{\text {sys }}$, the Equivalent Noise Bandwidth of the High Frequency section, $\mathrm{B}_{\mathrm{HF}}(\mathrm{Hz})$, and the equivalent bandwidth of the Low Pass filter or integrating circuit $\left(\mathrm{B}_{\mathrm{LF}}\right)$ with an integration time constant $\tau(\mathrm{seg})=1 /\left(2 \mathrm{~B}_{\mathrm{LF}}\right)[8]$, and is expressed as:

$$
\Delta \mathrm{T}=\frac{\mathrm{T}_{\text {sys }}}{\sqrt{\mathrm{B}_{\mathrm{HF}} \tau}}
$$

where a high gain is assumed and gain-noise fluctuations are neglected.

Receiver gain and noise fluctuations worsen this sensitivity. The Dicke receiver implements a synchronous detection [10-12] which diminishes the decrease in sensitivity due to these fluctuations. It is based on measuring periodically, switching between the power received from the antenna and the received from a load at the temperature of reference. The drawback is that, as the signal of interest is only received half of the time, the sensitivity is half that of a total power receiver, given by

$$
\Delta \mathrm{T}=\frac{2 \mathrm{~T}_{\text {sys }}}{\sqrt{\mathrm{B}_{\mathrm{HF}} \tau}}
$$

Traditionally super-heterodyne topology is well suited to process the signal mostly in lower frequencies, including multichannel filter banks or digital spectrometers, for example. For total power measurements, direct detection radiometers may provide a simple solution as long as high-frequency, low-noise amplifiers, filters, and detectors are available.

In this work, the design and characterization of W-band radiometers with superheterodyne and direct detection topologies are presented, operating as a total power radiometer and as a Dicke radiometer, allowing by extrapolation the evaluation of W-band instruments composed of a group of those receivers. Previous works have presented the development and characterization of the opto-mechanical components (antenna front-end) and the design and optimization of a polarimeter in W-band [13,14], as well as the use of a total power radiometer with direct detection in W-band for imaging systems [15].

This paper is structured as follows: In Section 2, the two topologies under consideration (super-heterodyne and direct detection) are described. Details are given of all the constituting subsystems. Then, in Section 3, simulation procedures for both operation modes: total power and Dicke mode are described and applied to both topologies. In Section 4 characterization of assembled radiometers operating in the described modes is shown, allowing the comparison between topologies and operation modes for the given subsystems. Comparisons with other reported W-band radiometers are shown. Conclusions are drawn in Section 5.

\section{W-Band Radiometer Topologies}

The total power radiometer developed in the super-heterodyne version is divided into three main parts: a front-end module with low noise amplification and band-pass filtering in W-band (RF), an intermediate frequency section (IF) with amplification, and, finally, quadratic-law diode detection. A schematic block diagram of the super-heterodyne radiometer is shown in Figure 1. 


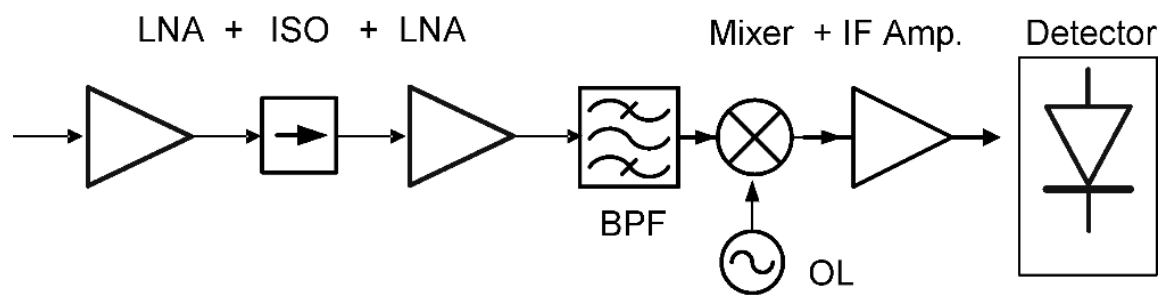

Figure 1. W-band super-heterodyne radiometer.

Amplification in the front-end consists of two low noise amplifiers interconnected by means of a low-loss isolator. Subsequently, the signal is filtered in the W-band using a waveguide band-pass filter (BPF) and converted to IF using a sub-harmonic mixer. After mixing, the IF signal is amplified by means of a broadband amplifier, and the signal is then converted to DC with a quadratic-law diode detector. It should be noted that the IF bandwidth of the mixer may contribute to narrow the system bandwidth determined by the BPF.

In the direct-detection version, the IF section is omitted and RF front-end output is applied directly to a W-band detector (see Figure 2).

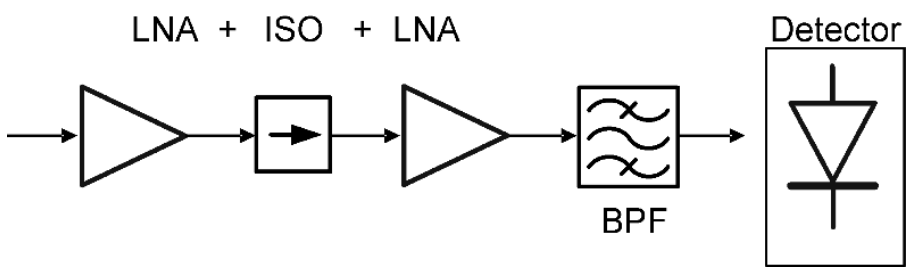

Figure 2. W-band direct detection radiometer.

Next, the subsystems that constitute the radiometers are described.

\subsection{Low Noise Amplifiers in W Band}

The low noise amplifiers (LNA) used in the W-band are commercial microwave monolithic integrated circuits (MMIC), which have been mounted on a custom-designed chassis with microstrip transitions to waveguide WR-10.

The first amplifier is from OMMIC (model CGY2190UH/C2). It is an MMIC designed in $70 \mathrm{~nm}$ high electron mobility transistor (HEMT) metamorphic technology. Mounted on the chassis with transitions to guide WR-10, it provides a gain above $25 \mathrm{~dB}$ from 75 to $105 \mathrm{GHz}$ and a noise around $3.5 \mathrm{~dB}$, with a nominal DC power consumption of $39.6 \mathrm{~mW}$. The results of gain and noise are shown in Figure 3.

The second amplifier is an LNA from NGC, model ALP283. This amplifier is made with $100 \mathrm{~nm}$ Indium Phosphide (InP) HEMT technology. This MMIC provides nominally gain around $30 \mathrm{~dB}$ and noise figure around $3.5 \mathrm{~dB}$ in the band from 80 to $100 \mathrm{GHz}$, for a DC bias consumption around $30 \mathrm{~mW}$ as shown in Figure 3. It should be considered that, in general, custom assembly might worsen on wafer performance due to additional losses and other effects [16]. DC bias point has been slightly tuned from the nominal one provided by the manufacturer in each setup.

For the measurement of gain and noise, a noise figure analyzer (NFA8975A from Keysight Technologies, Santa Rosa, CA, USA) was used together with the QHSW3FBDO down-converter mixer by Quinstar. Those measurements have been made at a fixed IF of $100 \mathrm{MHz}$, with a W-band noise source model QNSFB12LW by Quinstar, with an excess noise ratio (ENR) of about $15 \mathrm{~dB}$ in the whole band.

Both LNAs were connected by means of an HP WR365A isolator to avoid mismatching between both amplifiers and to prevent gain ripple. The isolator shows insertion loss of about $1.5 \mathrm{~dB}$ and provides isolation over $25 \mathrm{~dB}$ in the $\mathrm{W}$ band (Figure 4 ). 


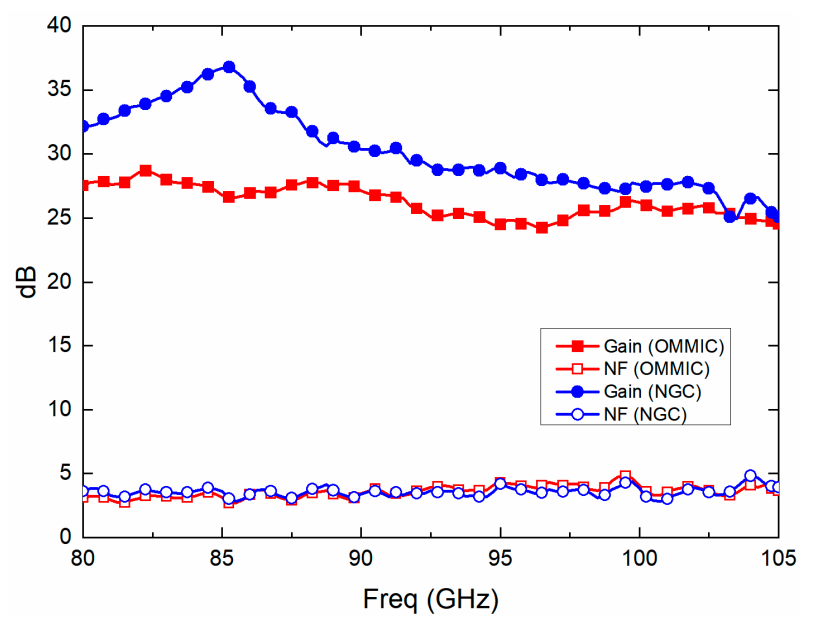

Figure 3. Gain and noise of MMIC LNAs: CGY2190UHC2 (OMMIC) $P_{\mathrm{DC}}=39.6 \mathrm{~mW}$; and ALP283 (NGC) $P_{\mathrm{DC}}=30 \mathrm{~mW}$.

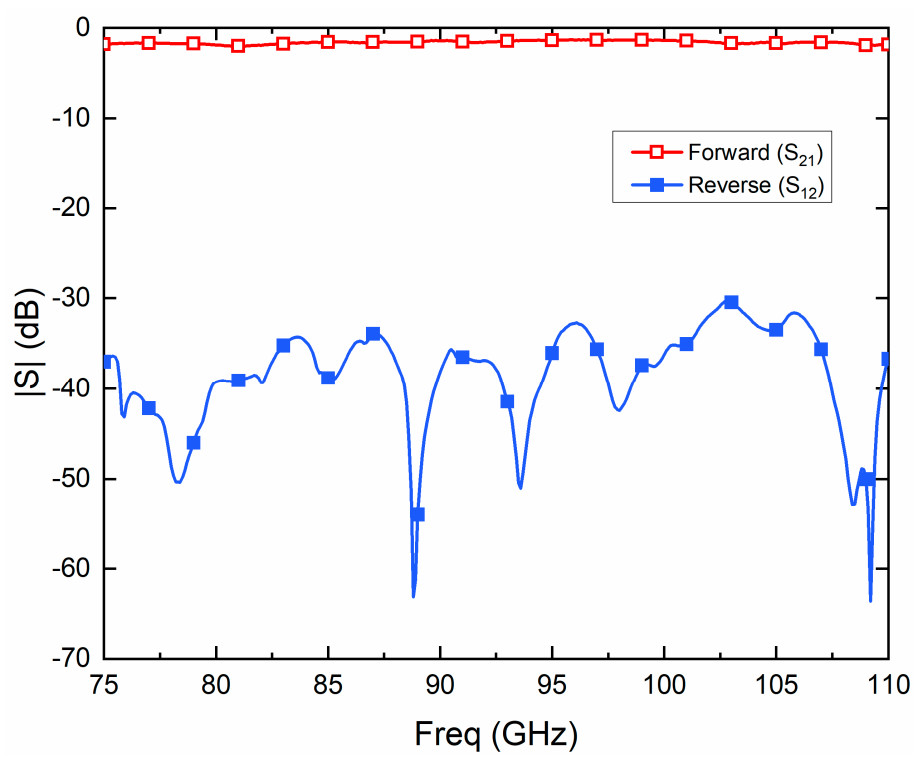

Figure 4. Forward (S21) and reverse (S12) gain of HPWR365A Isolator.

To provide a perspective of the technology of $\mathrm{W}$ band LNAs at room temperature, Table 1 lists a comparison of the LNAs employed in this setup with other references from different technologies. It should be mentioned that SiGe technologies [17] could provide lower consumption than GaAs based metamorphic or InP HEMT, but with slightly higher noise figures. Even $\mathrm{GaN}$ technology [18] can provide similar noise figures, but with higher consumption, as could be expected from a technology conceived to handle higher power levels than the typical for LNAs. In addition, it should be mentioned that some of the LNA performances listed in Table 1 correspond to on wafer measurements, which differs from on chassis mounted [16].

Table 1. LNAs performance comparisons.

\begin{tabular}{|c|c|c|c|c|c|}
\hline Reference & Technology & $\mathrm{B}_{3 \mathrm{~dB}}(\mathrm{GHz})$ & NF (dB) & \multicolumn{2}{|c|}{ Gain PDC mW } \\
\hline [16] & Ommic. Mounted & 75-105 & 4.4 & 14.9 & - \\
\hline [17] & $0.13 \mu \mathrm{m} \mathrm{SiGe}$ & $70-87$ & 4.2 & 22.3 & 8 \\
\hline [18] & $\mathrm{GaN}$ & $86-98$ & 3.8 & 20 & 128 \\
\hline This work: Ommic CGY2190UH & $70 \mathrm{~nm}$ methamorphic HEMT mounted & 75-105 & 3.5 & 25 & 39.6 \\
\hline This work: NGC ALP283 & 100 nm InP HEMT mounted & $80-100$ & 3.5 & 35 & 30 \\
\hline
\end{tabular}




\subsection{Bandpass Filter}

The Band Pass Filter (BPF) is a waveguide filter that covers the band $80.1-101 \mathrm{GHz}$ ( $3 \mathrm{~dB}$ bandwidth over $23 \%$ ) and in-band insertion losses of about $0.4 \mathrm{~dB}$. The design details and measurements obtained from different prototypes of the filter can be found elsewhere [19].

\subsection{Sub-Harmonic Mixer}

A commercial sub-harmonic mixer of Quinstar, model QHSW3FBDO, is used to convert to intermediate frequency in the super-heterodyne version. It is a third-harmonic mixer with low conversion losses and a wide IF bandwidth. It works over the whole $\mathrm{W}$-band $(75-110 \mathrm{GHz})$ and is suitable for super-heterodyne radiometer implementation in the laboratory using a low-frequency source as the local oscillator (LO) $(1 / 3$ of $\mathrm{W}$ band). It has a WR-10 waveguide for RF input and a diplexer for both, the input of the local oscillator signal and the IF output.

$\mathrm{LO}$ frequency can be tuned between 25 and $36 \mathrm{GHz}$. A value of $27.1 \mathrm{GHz}$ with $8 \mathrm{dBm}$ power has been used in the receiver, providing a conversion loss of around $15 \mathrm{~dB}$ in a range of intermediate frequencies (IF) from 0.1 to $15 \mathrm{GHz}$. This range narrows the system bandwidth. In Figure 5 the measured conversion loss of the mixer is shown over the RF frequency. Conversion loss has been estimated from the total gain measurement of the two $\mathrm{W}$-band amplifiers together with the isolator, the BPF and the mixer, and discounting the gains of each amplifier and the insertion losses of the insulator and the filter, respectively. A significant increase in losses over $96 \mathrm{GHz}$ must be noted, as it is considered that it will contribute to narrow the effective bandwidth and noise performance. Nevertheless, the IF bandwidth exceeds by far the nominal value in the mixer datasheet. About LO to IF isolation, a value of $31.36 \mathrm{dBc}$ is obtained from the manufacturer's datasheet for a $27.1 \mathrm{GHz}$ LO. Considering that the IF bandwidth is around $15 \mathrm{GHz}$, signal leakage at $27.1 \mathrm{GHz}$ is far from the falling edge of conversion losses, therefore it is not considered a concern.

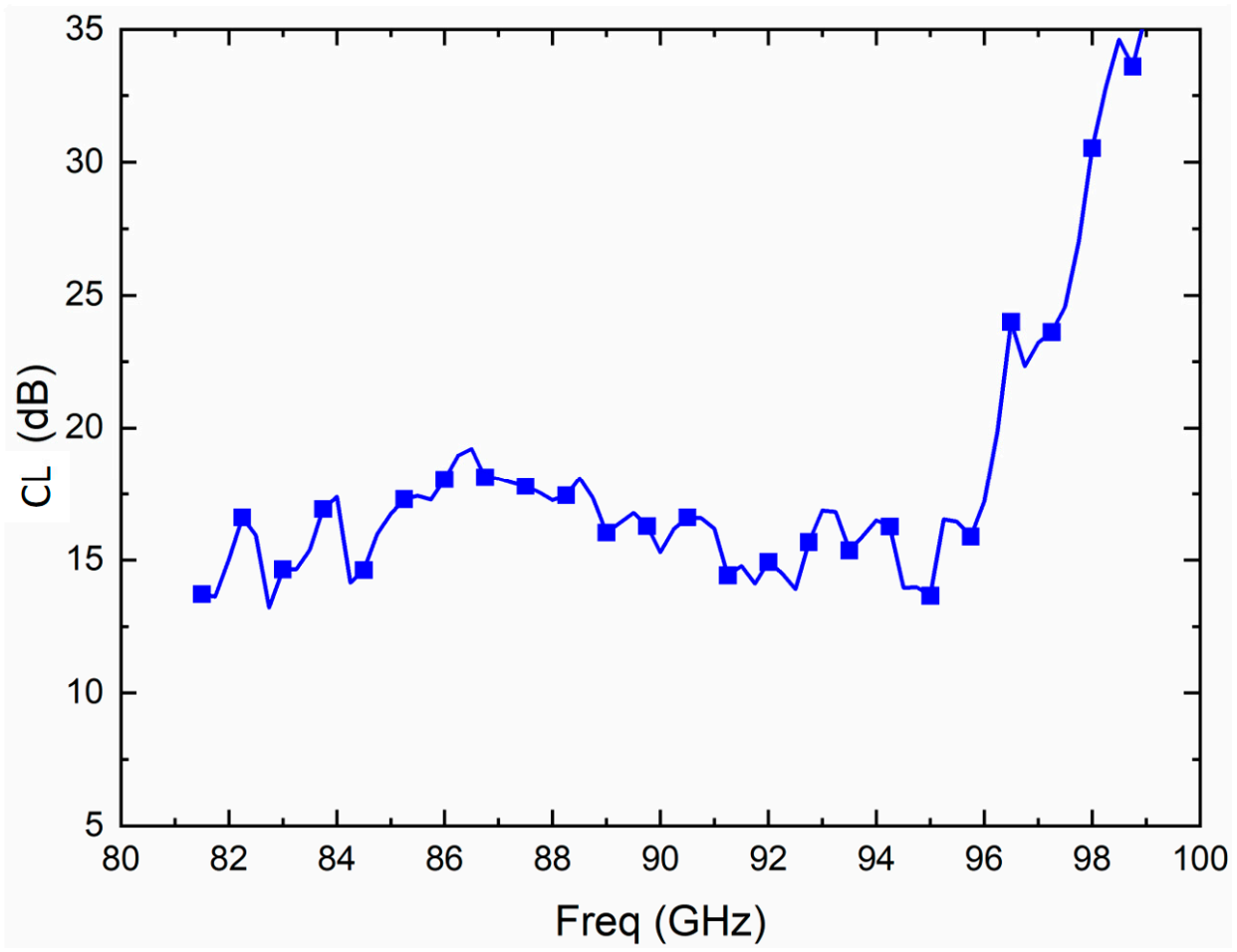

Figure 5. Measured conversion loss of the QHSW3FBDO mixer for a LO frequency of $27.1 \mathrm{GHz}$ and power of $8 \mathrm{dBm}$. 
The mixer is expected to add a relatively small contribution to the total system noise, since it is placed after the two amplifiers providing both together a gain above $40 \mathrm{~dB}$.

\subsection{IF Amplifier}

The intermediate frequency amplifier is a Triquint distributed amplifier; model TGA2513, fabricated in $0.15 \mu \mathrm{m}$ gallium arsenide (GaAs) pseudomorphic HEMT (pHEMT) technology. This amplifier works from 0.5 to $23 \mathrm{GHz}$ with a gain of around $15 \mathrm{~dB}$ and noise figure below $4 \mathrm{~dB}$, for a $\mathrm{DC}$ polarization of $\mathrm{Vd}=5 \mathrm{~V}$ and $\mathrm{Id}=90 \mathrm{~mA}$.

\subsection{IF Detector and Video Amplifier}

The diode detector HP8474E, which operates from $10 \mathrm{MHz}$ to $50 \mathrm{GHz}$ with a sensitivity of around $500 \mathrm{mV} / \mathrm{mW}$, has been used as a quadratic-law diode detector for the IF frequency.

The video amplifier is the low noise preamplifier SR560 from Stanford Research Systems, which allows buffering of the detector output, video amplification (low frequency) and provides the required low pass filtering, suitable to be tuned.

\subsection{W-Band Detector and Video Amplifier}

For the W-band detector, a waveguide-mounted (WR-10) commercial model 47326H1100 from Hughes was used (Figure 6 shows its measured responsivity in W-band and Figure 7 its input reflection coefficient). The video amplifier is the same model as in the IF case, SR560 low noise preamplifier model, from Stanford Research Systems.

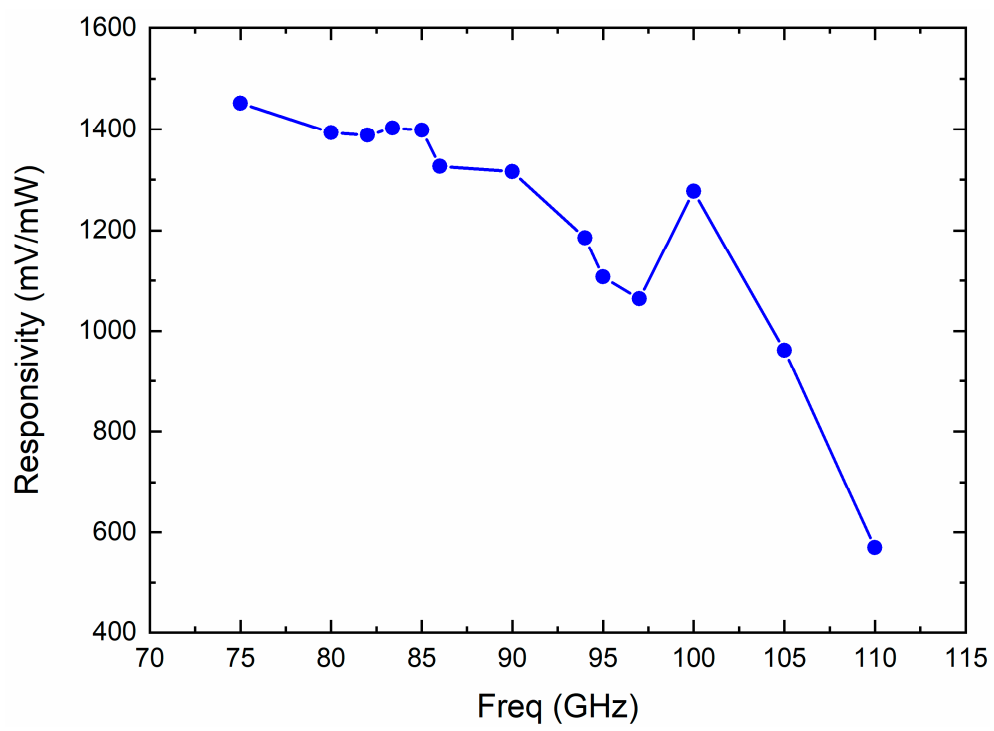

Figure 6. Measured detector responsivity over the W-band. 


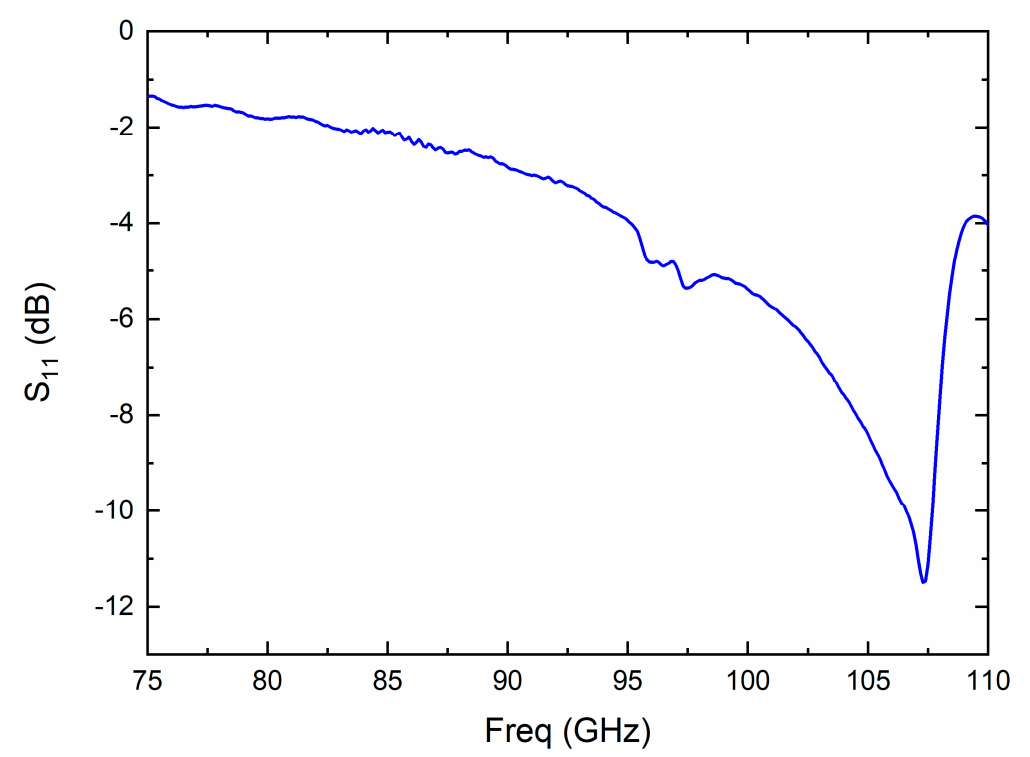

Figure 7. Measured input reflection of W-band detector.

\section{Radiometer Simulations: Total Power and Dicke Modes}

Mathematical developments of radiometer models are well known ([7-12]). Our scope in this section is to define a simulation procedure to predict radiometer performance, once the different constituting subsystems have been individually characterized, and taking into account the different modes of operation. Using the available data of the different subsystems (S-parameters and noise figure for amplifiers and filters, conversion losses versus frequency for the mixer, responsivity versus frequency for detectors) some system level simulations have been done [20] to address the foreseen behavior of both topologies: super-heterodyne and direct detection in total power mode and in Dicke mode. The behavior of a complex receiver is not easily emulated in a conventional RF circuit simulator, especially when its sub-systems are defined by their frequency domain parameters and it is excited by broadband noise-like signals and under switching operation. Therefore, the definition of an ad hoc procedure is required. For the total power mode, the simulation procedure (described in [15]) starts with the definition of the Equivalent Noise Bandwidth of a radiometer chain with gain $\mathrm{G}(\mathrm{f})$, given by [8]:

$$
B_{H F}=\frac{\left[\int G(f) d f\right]^{2}}{\int G^{2}(f) d f}
$$

which can be re-written in terms of detected output voltage, dependent on the input frequency [21]. This requires evaluating the output DC voltage of the detector when a single tone at a frequency $f=f_{i}$ is applied, which implies, in a first approach, neglecting any intermodulation or spectral regrowth. The fi frequency is swept across the entire band of interest. This sweep is discrete with $\mathrm{N}$ points and a frequency step $\Delta \mathrm{f}$. The noise floor is accounted for with an offset value $\mathrm{V}_{\text {outoff }}$, leading to the following expression:

$$
B_{H F}=\Delta f\left(\frac{N}{N+1}\right) \frac{\left(\sum_{i=1}^{N}\left(V_{\text {out }}\left(f_{i}\right)-V_{\text {out }_{\text {off }}}\right)\right)^{2}}{\sum_{i=1}^{N}\left(V_{\text {out }}\left(f_{i}\right)-V_{\text {out }_{\text {off }}}\right)^{2}}
$$

The actual operation of the radiometer occurs with a broadband noise input signal, which power depends on the noise temperature of the input load, switching between cold and hot states. To emulate this operation mode with Harmonic Balance (HB) simulations in the frequency domain, a frequency sweep of an equivalent tone, including system noise, is 
applied to the noiseless system. The Effective Noise Bandwidth $B_{H F}$ is required to compute the equivalent tone power. Therefore, a previous sweep in harmonic balance is done with an approximate power to estimate the Effective Noise Bandwidth under these conditions. Then, the resulting $B_{\mathrm{HF}}$, together with the values of equivalent noise temperature $\left(\mathrm{T}_{\mathrm{sys}}\right)$ of the system and temperature corresponding to the input power $\left(T_{R}\right)$ and the Boltzmann constant $(\mathrm{k})$, are used to calculate the power that the equivalent-in-power tone to broadband noise should have, as shown in expression:

$$
\mathrm{P}_{\text {Tone }}=\mathrm{k}\left(\mathrm{T}_{\mathrm{R}}+\mathrm{T}_{\text {sys }}\right) \mathrm{B}_{\mathrm{HF}}=\mathrm{kT}_{\mathrm{T}} \mathrm{B}_{\mathrm{HF}}
$$

In the HB simulation, the input signal is swept over the band, concentrating all the power at each frequency step: a single tone $@ f_{i}$ with a power level equivalent to the broadband noise is frequency-swept in band to have approximately the same compression as in actual operation. Therefore, the DC output voltage is estimated as an average of the DC output values of the frequency sweeping in the operation band:

$$
\mathrm{V}_{\text {outDC }}=\overline{\mathrm{V}_{\text {out }}\left(\mathrm{f}_{\mathrm{i}}\right) \mathrm{i}: 1 \ldots \mathrm{N}}
$$

Simulation of the radiometers in Dicke mode requires the use of transient envelope tools (to reproduce better the effect of modulation) and the modification of available models, particularly S-parameters, to be used in such a time-domain contest like in [22]. To implement the simulations, a CW carrier at $90 \mathrm{GHz}$ (in the center of the intended band) will be modulated by a square signal at a low frequency in the range of $100 \mathrm{~Hz}$, in agreement with the frequency applied to the available optical "chopper" to emulate switching between $\mathrm{ON}$ and OFF states. The $90 \mathrm{GHz}$ signal will be processed using Harmonic Balance and the envelope time scale will be determined by the $100 \mathrm{~Hz}$ modulating signal. In the case of the super-heterodyne radiometer, the local oscillator frequency should be included in the Harmonic Balance. In this operation mode the concern is not the detected output voltage raw, but processed comparing ON $\left(T_{R}=T_{\text {hot }}\right)$ and OFF $\left(T_{R}=T_{\text {cold }}=T_{0}=290 \mathrm{~K}\right)$ states: the $\mathrm{R}$ parameter defined as the Root Mean Square of the difference among detected voltage output at ON state and at OFF states [10]. R parameter and the use of the optical chopper will be further described in more detail.

Apart from sensitivity Equations (1) and (2), other figures of merit, like the Noise Equivalent Power (NEP) are commonly used to characterize detectors and by extension to complete radiometers including pre-amplification. NEP is defined in Equation (7), where TSS is the Tangential Sensitivity and its relationship with sensitivity Equations (1) and (2) is presented in Equation (8) where a detector is defined by its $\mathrm{NEP}_{\text {det }}$ with pre-amplification (gain G, Noise Temperature $T_{\text {sys }}$ ) is supposed [23]. In fact, Equation (1) is a simplification of Equation (8) if high gain is supposed. If no pre-amplification is considered (case of a stand-alone detector), only the second adding under the root in Equation (8) would remain with unit gain $(\mathrm{G}=1)$.

$$
\begin{gathered}
\mathrm{NEP}=\frac{\mathrm{TSS}}{\left(\mathrm{B}_{\mathrm{HF}}\right)^{1 / 2}} \\
\Delta \mathrm{T}=\sqrt{\left[\frac{2 \mathrm{~T}_{\mathrm{Sys}}^{2}}{\mathrm{~B}_{\mathrm{HF}}}+\left(\frac{\mathrm{NEPdet}}{\mathrm{kGB}_{\mathrm{HF}}}\right)^{2}\right] \frac{1}{2 \tau}}
\end{gathered}
$$

\subsection{Super-Heterodyne Radiometer in Total Power Operation}

According to the described procedure, the voltage profile response versus input frequency shown in Figure 8 was obtained with the super-heterodyne topology with the input tone power level corresponding to hot temperature, including also the power due to internal system noise. A Noise figure of $5 \mathrm{~dB}$ was estimated by simulation for the system, which corresponds to $\mathrm{T}_{\text {sys }}=644.35 \mathrm{~K}$. An $\mathrm{ENR}=15 \mathrm{~dB}$ converted to $\mathrm{T}_{\text {hot }}$ gives a value of $9721.6 \mathrm{~K}$. The estimated bandwidth was $18 \mathrm{GHz}$. Cold and hot estimated power 
values were $-66.3 \mathrm{dBm}$ and $-56.01 \mathrm{dBm}$, respectively. Considering cases for cold and hot temperature, two points could be marked and the line connecting both give us an estimation of the system responsivity about $1.5 \mu \mathrm{V} / \mathrm{K}$ (Figure 9). Assuming an integration time of $30 \mathrm{~ms}$, according to Equation (1), a value of $27.7 \mathrm{mK}$ could be estimated for $\Delta \mathrm{T}$.

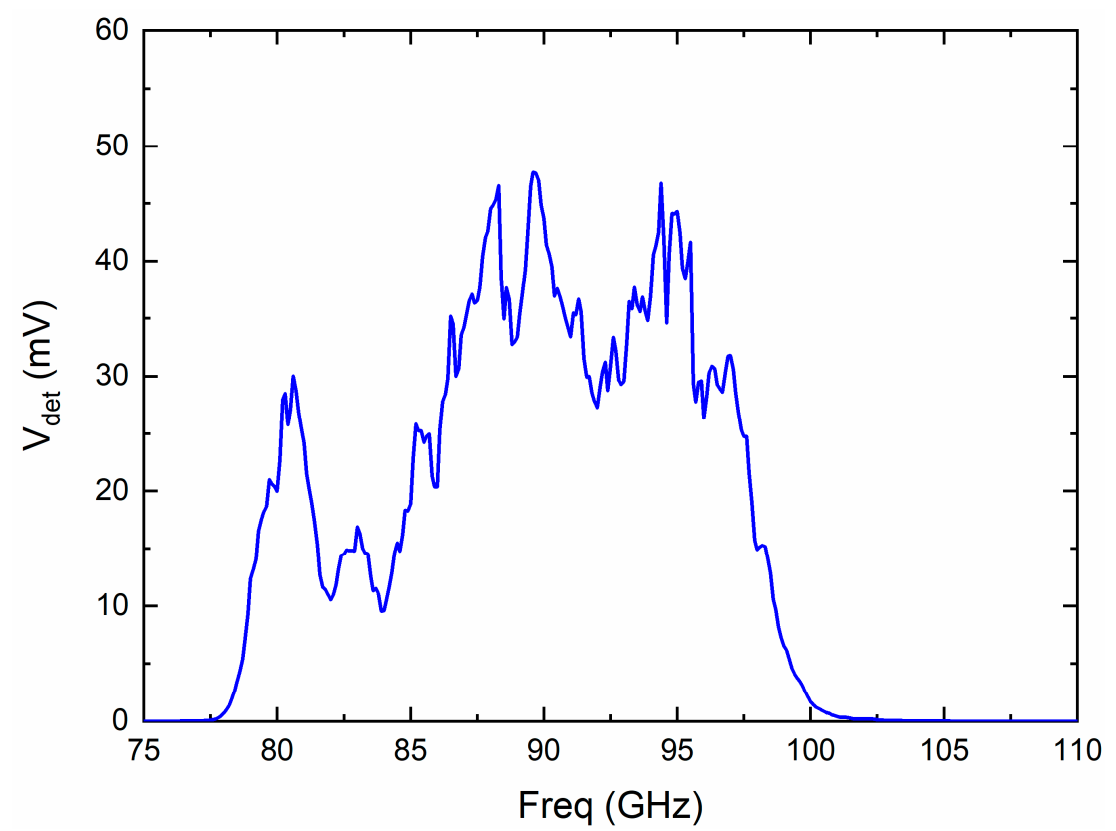

Figure 8. Simulated detected voltage versus input frequency for the super-heterodyne topology. Sweeping input tone $-56.01 \mathrm{dBm}\left(\mathrm{T}_{\text {sys }}+\mathrm{T}_{\text {hot }}\right)$, mean $\mathrm{V}_{\text {out }}: 16.04 \mathrm{mV}$ (hot point).

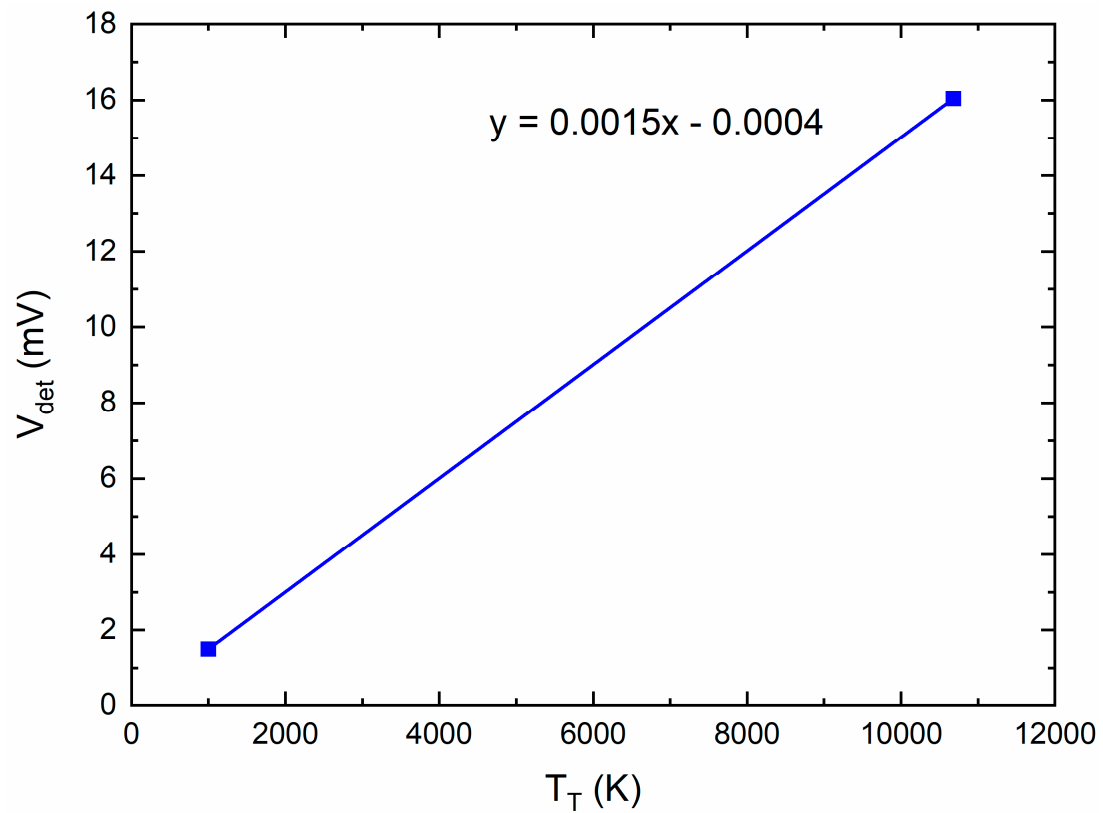

Figure 9. Simulated responsivity of the super-heterodyne radiometer when switching noise source between OFF and $\mathrm{ON}$ state (Temperature).

\subsection{Direct Detection Radiometer in Total Power Operation}

The same simulation was performed in the direct detection system, obtaining the Voltage profile response versus input frequency shown in Figure 10 with the input tone power level corresponding in this case to cold temperature (including equivalent power due to system noise). A noise figure of $4 \mathrm{~dB}$ was estimated by simulation for the system, 
which corresponds to $\mathrm{T}_{\text {sys }}=450.54 \mathrm{~K}$. $\mathrm{T}_{\text {hot }}$ is the same as in the previous case, $9721.6 \mathrm{~K}$. The estimated bandwidth was $20.57 \mathrm{GHz}$. Cold and hot power estimated were $-66.73 \mathrm{dBm}$ and $-55.52 \mathrm{dBm}$, respectively. Considering both cases for hot and cold temperatures, two points could be marked and the line connecting both gives us an estimated system responsivity of about $11.8 \mu \mathrm{V} / \mathrm{K}$ (Figure 11). Assuming an integration time of $30 \mathrm{~ms}$, a value of $18.39 \mathrm{mK}$ could be estimated for $\Delta \mathrm{T}$ according to Equation (1).

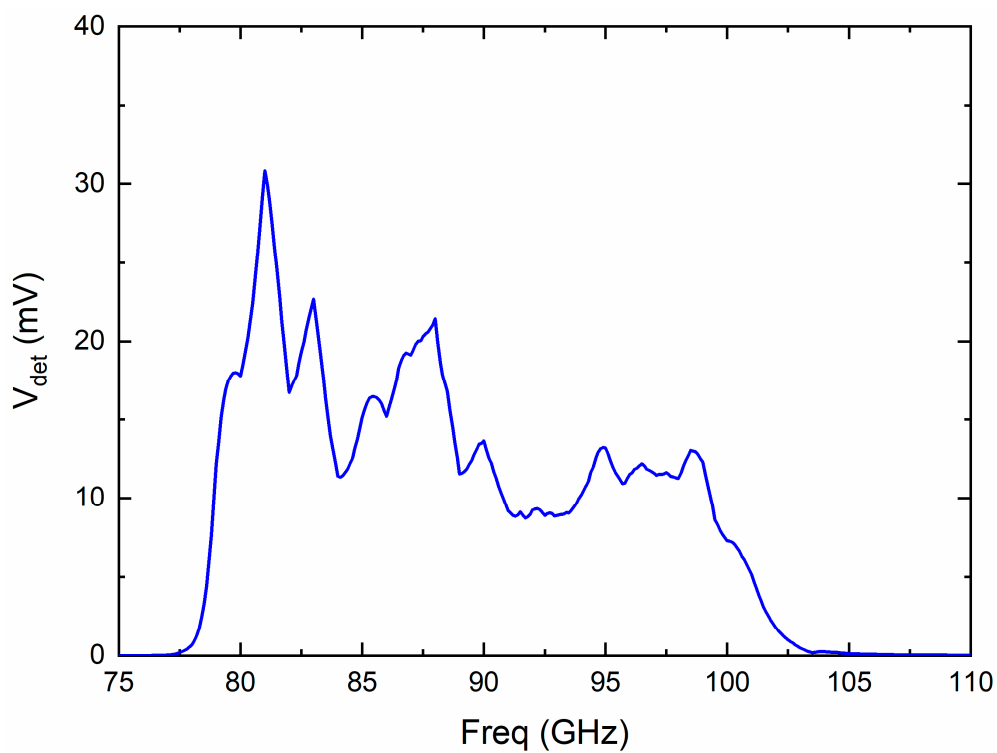

Figure 10. Simulated detected voltage versus input frequency for the direct detection topology. Sweeping input tone $-66.73 \mathrm{dBm}\left(\mathrm{T}_{\text {sys }}+\mathrm{T}_{\text {cold }}\right)$, mean $\mathrm{V}_{\text {out }}$ : $9.1 \mathrm{mV}$ (cold point).

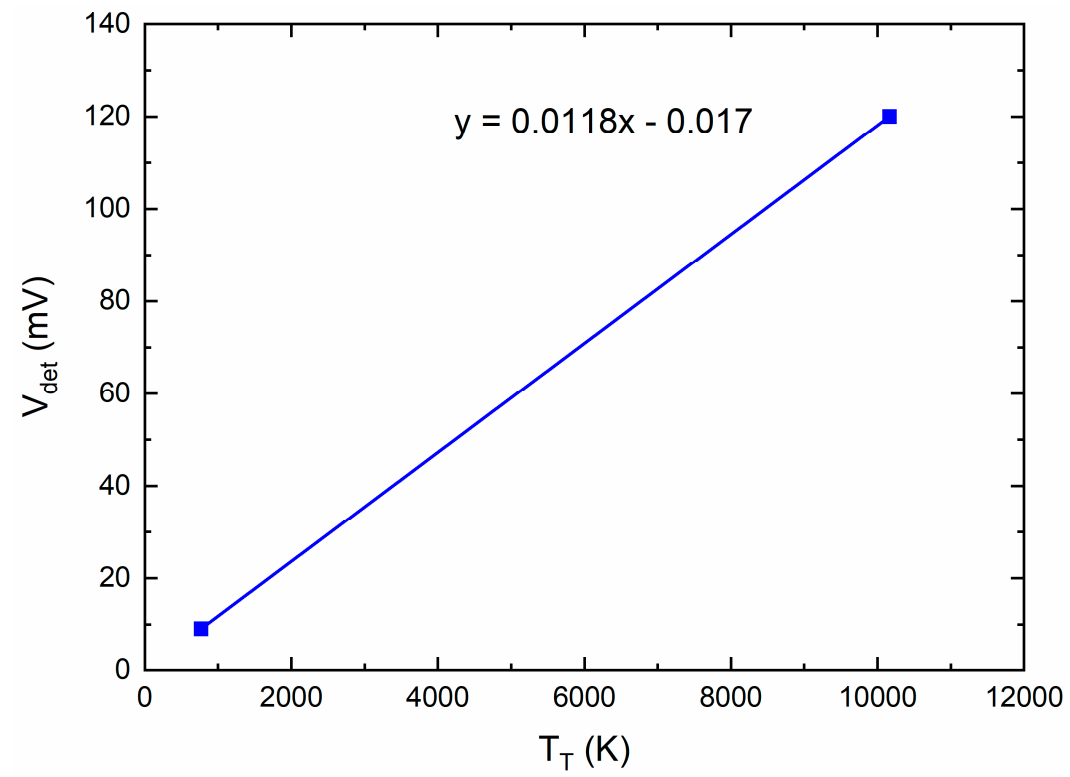

Figure 11. Simulated responsivity of the direct detection radiometer when switching noise source between OFF and ON state (Temperature).

\subsection{Comparison of Super-Heterodyne and Direct Detection Radiometers in Total Power Operation}

Table 2 summarizes the comparison of simulated results for both topologies in total power operation. The noise figure of radiometers is dominated by the RF front-end contribution, therefore the expected value of $3.5 \mathrm{~dB}$ should be almost maintained when adding the different back-end contributions. A worst-case with an averaged in-band noise 
figure of $4 \mathrm{~dB}$ for direct detection or $5 \mathrm{~dB}$ for heterodyne detection has been assumed, according to simulated results supposing some additional losses, to calculate the input power equivalent to system noise.

Table 2. Total Power radiometer simulations for both, super-heterodyne and direct detection radiometers.

\begin{tabular}{cccccccccc}
\hline Topology & $\mathbf{B}_{\mathrm{HF}}(\mathrm{GHz})$ & $\mathbf{N F}(\mathbf{d B})$ & $\boldsymbol{\Delta} \mathbf{T}(\mathbf{m K})$ & $\begin{array}{c}\text { Pin Cold } \\
(\mathbf{d B m})\end{array}$ & $\begin{array}{c}\text { Vmean } \\
\text { Cold }(\mathbf{m V})\end{array}$ & $\begin{array}{c}\text { Pin Hot } \\
(\mathbf{d B m})\end{array}$ & $\begin{array}{c}\text { Vmean } \\
\text { Hot }(\mathbf{m V})\end{array}$ & $\begin{array}{c}\text { Responsivity } \\
(\mathbf{m V} / \mathbf{m W})\end{array}$ & $\begin{array}{c}\text { Responsivity } \\
(\boldsymbol{\mu} \mathbf{V} / \mathbf{K})\end{array}$ \\
\hline RF Chain & 20.91 & 3.5 & - & - & - & - & - & - & - \\
RF + mix IF & 17.8 & 5 & 27.72 & -66.3 & 1.5 & -56.01 & 16.04 & $6 \times 10^{6}$ & 1.5 \\
$\quad+\operatorname{det~IF~}$ & 20.56 & 4 & 18.39 & -66.73 & 9.1 & -55.52 & 120.03 & $4 \times 10^{7}$ & 11.8 \\
RF + det W & & & & & & & &
\end{tabular}

\subsection{Super-Heterodyne Radiometer in Dicke Operation}

For the simulations, the power of an ON-OFF modulated $90 \mathrm{GHz}$ input tone has been arbitrarily swept from $-105 \mathrm{dBm}$ to $-55 \mathrm{dBm}$. Based on the time evolution of output voltage, switching between two states at a low frequency of $100 \mathrm{~Hz}$, an $\mathrm{R}$ parameter is defined averaging the difference between $V_{\text {out }}(\mathrm{ON})$ and $\mathrm{V}_{\text {out }}(\mathrm{OFF})$. The evolution of the $R$ parameter versus input power and versus input equivalent temperature (Figure 12) has been represented to determine system responsivity. A value of $4.6 \mu \mathrm{V} / \mathrm{K}$ has been found. Further description of $R$ parameter is given in Equation (12), in Section 4.1.2.

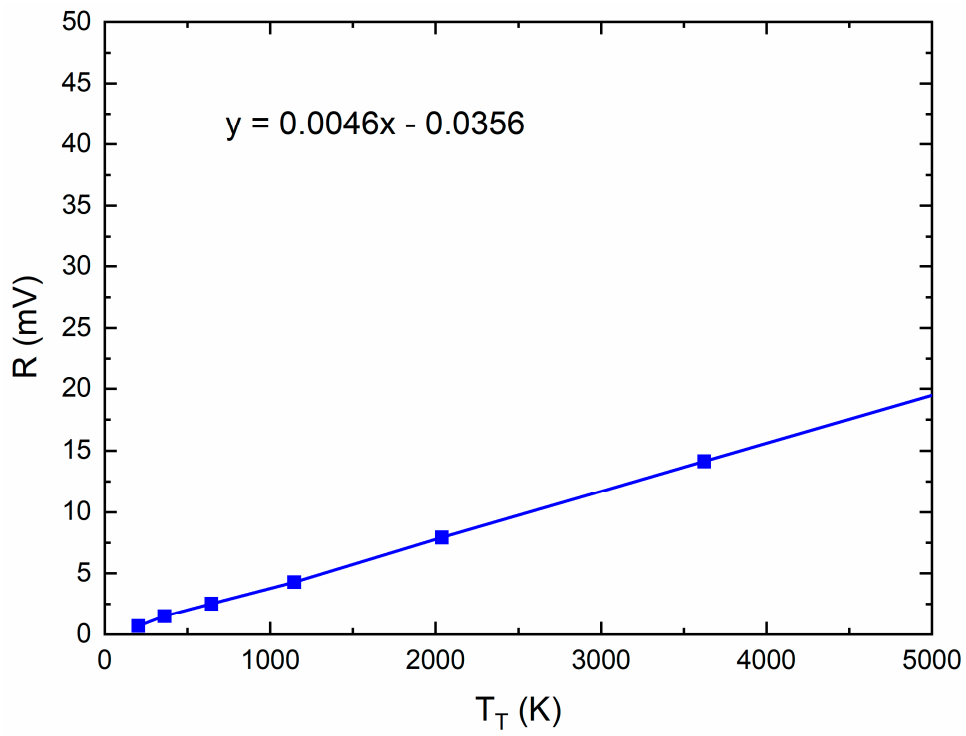

Figure 12. Simulated responsivity through $\mathrm{R}$ parameter of the super-heterodyne radiometer in Dicke operation mode versus input power (temperature $\mathrm{T}_{\mathrm{T}}$ ).

\subsection{Direct Detection Radiometer in Dicke Operation}

As in the previous case, the power of a $90 \mathrm{GHz}$ input tone has been arbitrarily swept from $-105 \mathrm{dBm}$ to $-57.5 \mathrm{dBm}$. The time evolution of the output voltage is shown in Figure 13. Based on it, the $\mathrm{R}$ parameter is obtained and a system responsivity of $6.4 \mu \mathrm{V} / \mathrm{K}$ has been found in this case (Figure 14), higher than the super-heterodyne radiometer, in agreement with the trend observed in total power responsivity.

\subsection{Comparison of Super-Heterodyne and Direct Detection Radiometers in Dicke Operation}

Table 3 summarizes the comparison of simulated responsivities and sensitivities of the four cases: super-heterodyne in total power mode, super-heterodyne in Dicke operation, direct detection in total power mode and direct detection in Dicke operation. The improvement in responsivity is clear for the super-heterodyne topology (from 1.5 to $4.6 \mu \mathrm{V} / \mathrm{K}$ ) but not for the case of direct detection. An integration time $\tau=30 \mathrm{~ms}$ is 
supposed for the sensitivity. The higher sensitivity of direct detection scheme is related to the broader bandwidth and to a slightly lower noise figure [23,24].

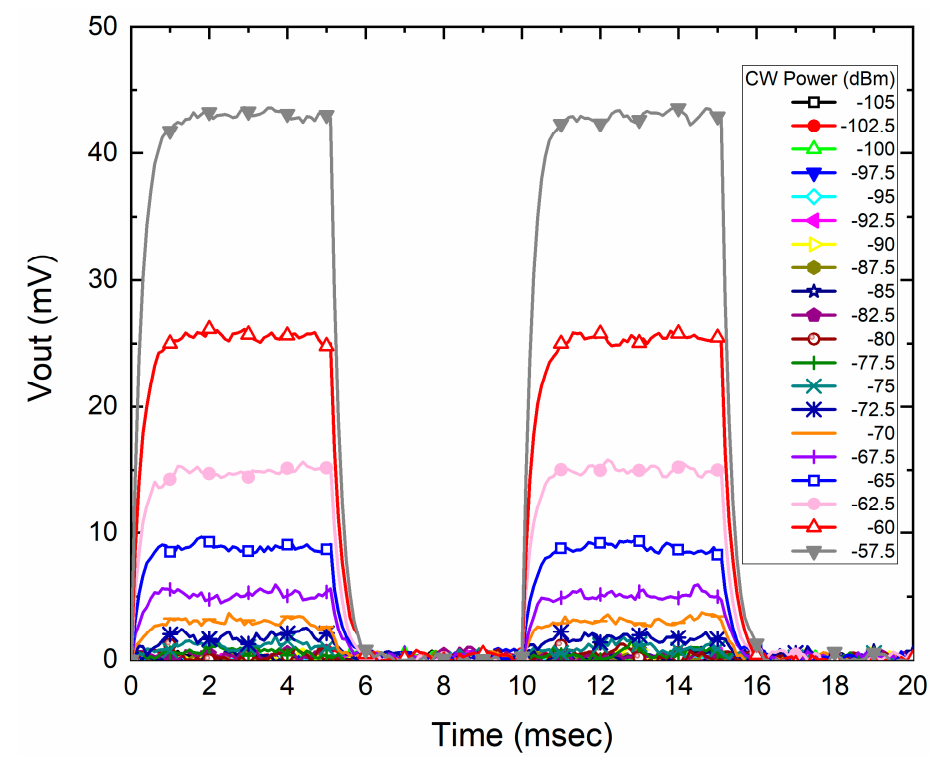

Figure 13. Simulated time domain (transient enveloped) response of the direct detection radiometer under Dicke operation mode for several input power levels.

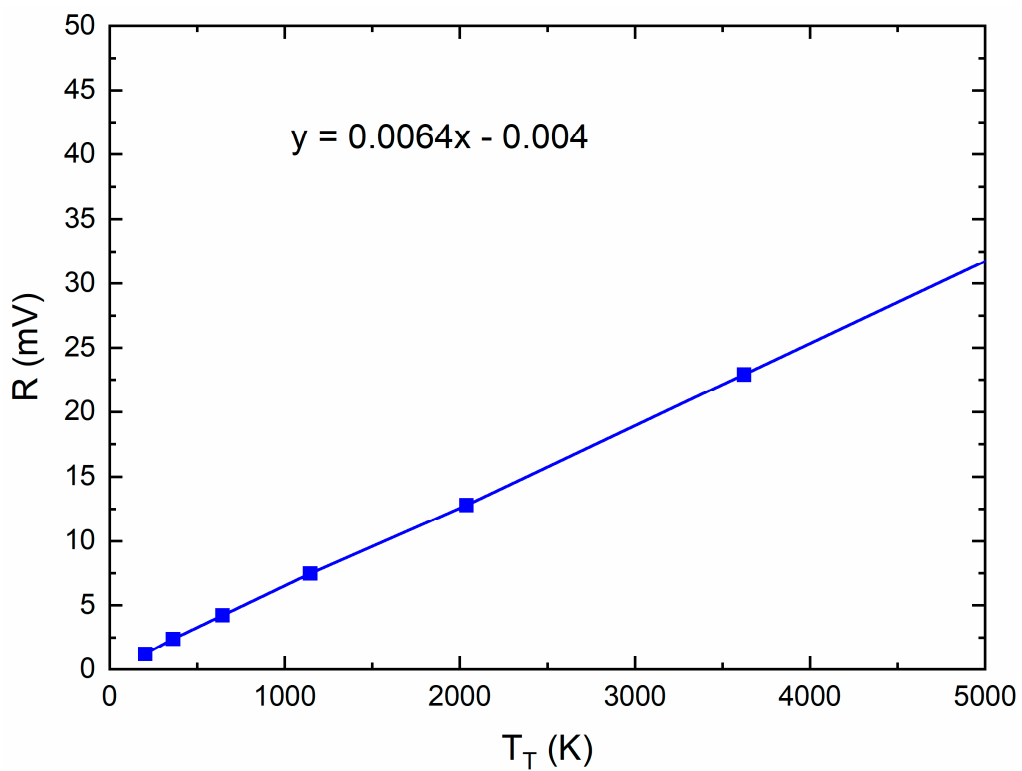

Figure 14. Simulated responsivity through $\mathrm{R}$ parameter of the direct detection radiometer in Dicke operation mode when the input power (temperature $\mathrm{T}_{\mathrm{T}}$ ) is swept.

Table 3. Simulated Responsivities in Total Power and Dicke operation modes for both, super-heterodyne and direct detection radiometers.

\begin{tabular}{|c|c|c|c|c|c|c|}
\hline Topology & $\begin{array}{l}\text { Responsivity } \\
\text { Total Power } \\
(\mathrm{mV} / \mathrm{mW})\end{array}$ & $\begin{array}{c}\text { Responsivity } \\
\text { Total Power } \\
(\mu \mathrm{V} / \mathrm{K})\end{array}$ & $\begin{array}{c}\text { Responsivity } \\
\text { Dicke } \\
(\mu \mathrm{V} / \mathrm{K})\end{array}$ & $\begin{array}{c}\Delta \mathrm{T} \\
\text { Total Power } \\
(\mathrm{mK})\end{array}$ & $\begin{array}{c}\text { NEP } \\
\text { pW/sqrt(Hz) }\end{array}$ & $\begin{array}{c}\Delta \mathrm{T} \\
\text { Dicke } \\
(\mathrm{mK})\end{array}$ \\
\hline $\begin{array}{l}\text { Super-heterodyne: } \\
\text { RF + mixIF + det }\end{array}$ & $6 \times 10^{6}$ & 1.5 & 4.6 & 27.72 & 0.0018 & 55.44 \\
\hline $\begin{array}{l}\text { Direct Det.: } \\
\text { RF + det W }\end{array}$ & $4 \times 10^{7}$ & 11.8 & 6.4 & 18.39 & 0.0015 & 36.78 \\
\hline
\end{tabular}




\section{Characterization of Radiometers}

The results of the experimental characterization of the whole systems, front-end RF section combined with the IF section or with the W-band detection, are presented in this section, as well as the measurement process.

\subsection{Super-Heterodyne Radiometer}

The super-heterodyne configuration has been characterized in gain and noise from the input of the first band amplifier $\mathrm{W}$ to the output of the IF amplifier. A fixed LO frequency of $27.1 \mathrm{GHz}$ with $8 \mathrm{dBm}$ has been used. The noise figure analyzer (NFA8975A) has been used, performing the calibration with a low frequency noise source HP346B and the measurement with the W-band noise source (QNSFB12LW) and a variable attenuator in W-band (Hitachi W1513, usingWR10 interface) at its output. The variable attenuator has been fixed to $9 \mathrm{~dB}$ in order to avoid saturation of the second amplifier when the source is in an "on" state. The gain and noise figure result in the Upper Side Band (USB) of the entire receiver, including the $9 \mathrm{~dB}$ attenuation, before detecting IF are shown in Figure 15. The gain in the operating band, including the conversion, is around $48 \mathrm{~dB}$ and averaged noise figure is about $3.92 \mathrm{~dB}$, which corresponds to an equivalent noise temperature $T_{\text {sys }}$ about $425 \mathrm{~K}$, slightly higher than the simulated for the RF front-end chain, but lower than predicted by simulations of the whole system, which also included additional losses and final detection.

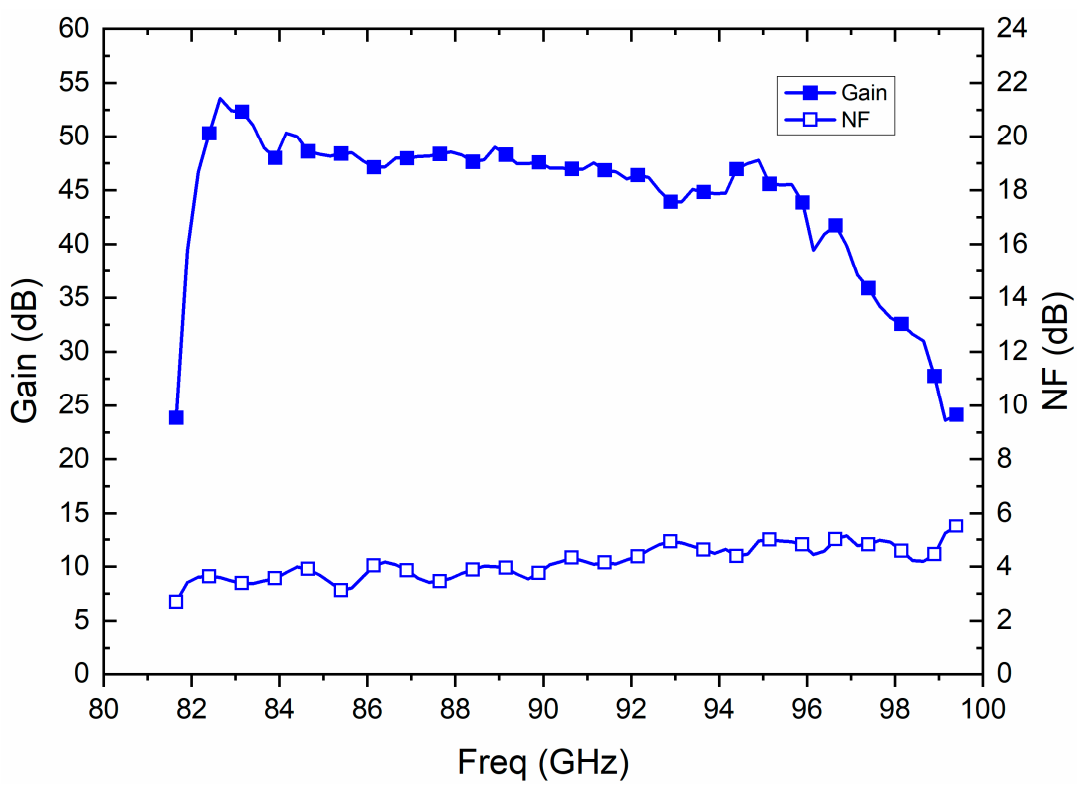

Figure 15. Gain and noise figure of the $\mathrm{W}$-band receiver composed of the two $\mathrm{W}$-band amplifiers with the isolator, the BPF, $9 \mathrm{~dB}$ attenuation, the mixer and the IF amplifier.

With this measure of gain and noise, the effective bandwidth of the radiometer has been calculated by applying (3), and a value of $10.7 \mathrm{GHz}$, lower than expected from simulations, has been obtained.

Supposing an ideal radiometer without gain fluctuations, the sensitivity of the radiometer could be calculated by applying (1) or (2), depending on the type of radiometer. For a bandwidth of $10.7 \mathrm{GHz}$, a system temperature of $425 \mathrm{~K}$ and taking an integration time $\tau$ of $30 \mathrm{~ms}$ the ideal sensitivities (Equations (1) and (2)) would be $24 \mathrm{mK}$ and $48 \mathrm{mK}$, for a total power radiometer and a Dicke radiometer, respectively. Both measurements, one as total power radiometer and another as Dicke radiometer, have been made. Sensitivities estimated are higher than the ideal ones due to additional losses, gain fluctuations and $1 / \mathrm{f}$ noise.

For these measurements, a W-band feed-horn antenna model QSH27F20 was connected to the receiver, with a gain of about $20 \mathrm{dBi}$. As a transmitter, the broadband noise 
source in W-band (QNSFB12LW), the wideband attenuator W1513 and another QSH27F20 antenna were used. For the Dicke operation mode, in-between both horn antennas, an optical chopper is placed as modulating component, switching ON and OFF the received signal, commanded by a low-frequency oscillator, also used to synchronize the detection. In total power operation, the optical chopper is absent and there is not any modulation nor synchronized detection.

In Figure 16 a photo of the complete system for Dicke mode evaluation is shown. The distance between the antennas is $2.74 \mathrm{~cm}$, which corresponds to near field conditions as the diagonal of the horn is in the range of $17 \mathrm{~mm}$, so far field distance is about $17.5 \mathrm{~cm}$ at $94 \mathrm{GHz}$ ). Losses of the link between both horns at a distance of $2.74 \mathrm{~cm}$ are estimated at $0.53 \mathrm{~dB}$ at $94 \mathrm{GHz}$. The chopper can be seen placed in-between both horns.

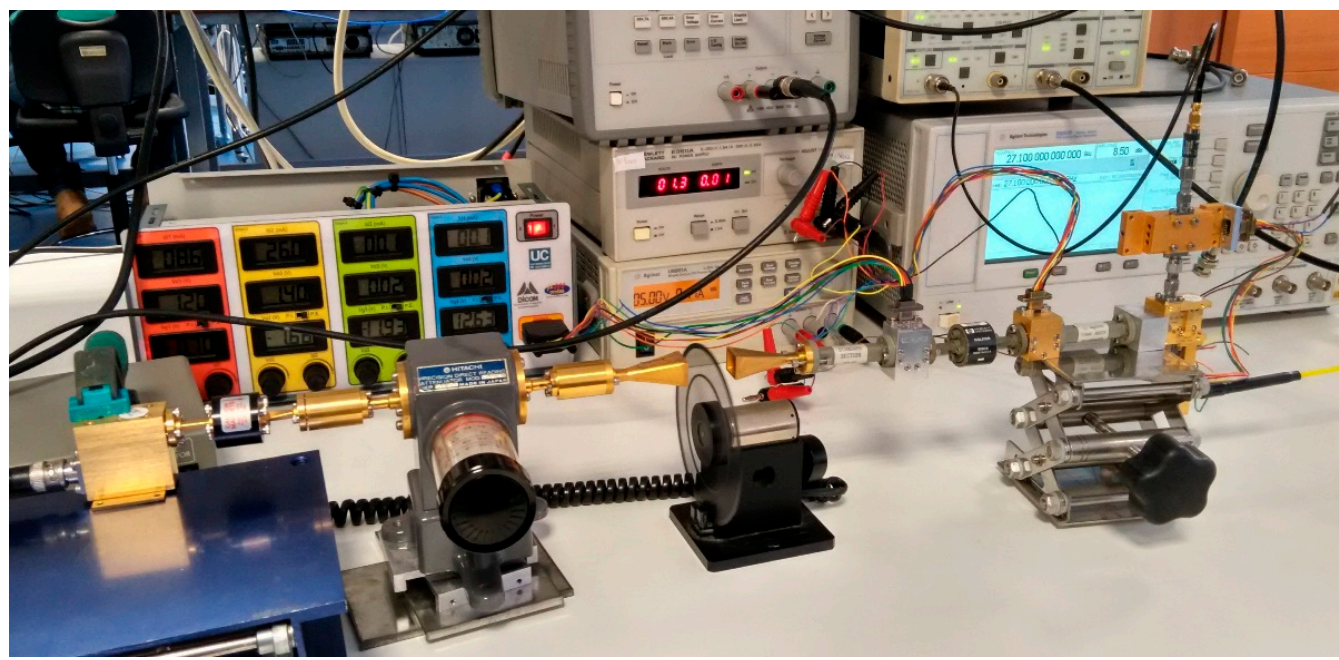

Figure 16. Photograph of the laboratory setup with the measurement system of the W-band superheterodyne radiometer in Dicke mode.

The effect of the chopper blade in between both horns has been simulated with Ansys ${ }^{\circledR}$ HFSS (High Frequency Structural Simulator) (Figure 17), finding a minimum variation of the radiation pattern when the blade is in the opening position, compared to the horn standalone, as can be seen in Figure 18.

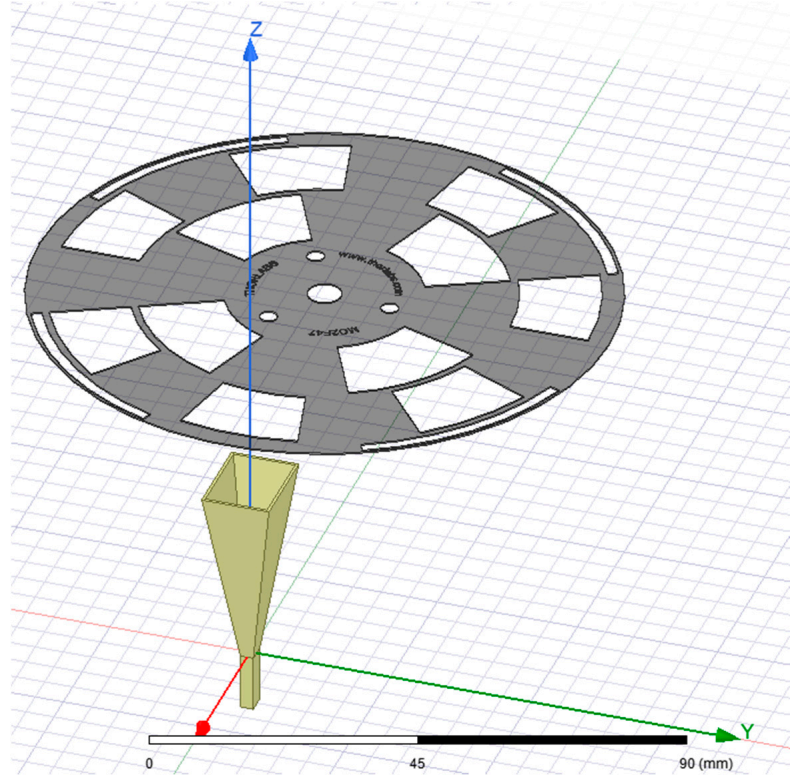

Figure 17. Drawing for the simulation of the effect of the chopper blade in front of the horn antenna. 


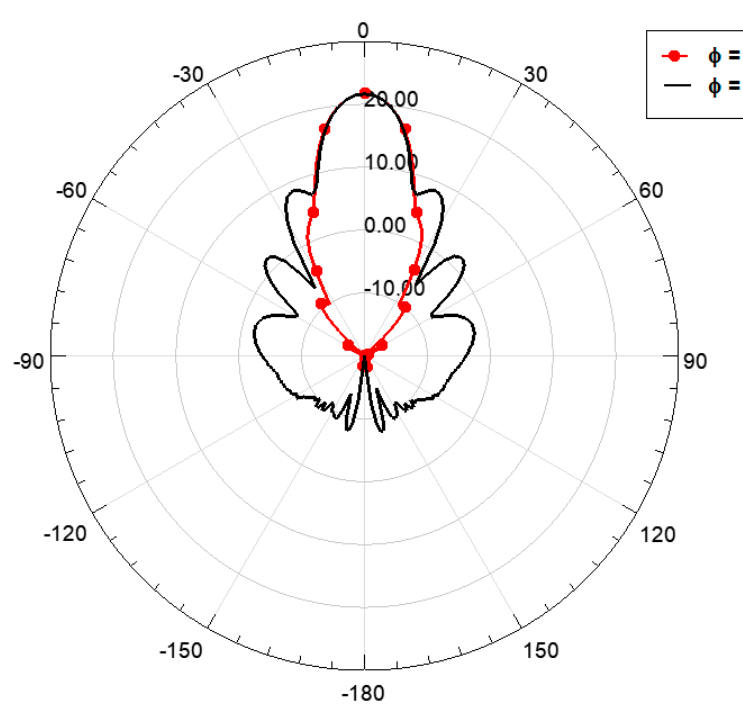

(a)

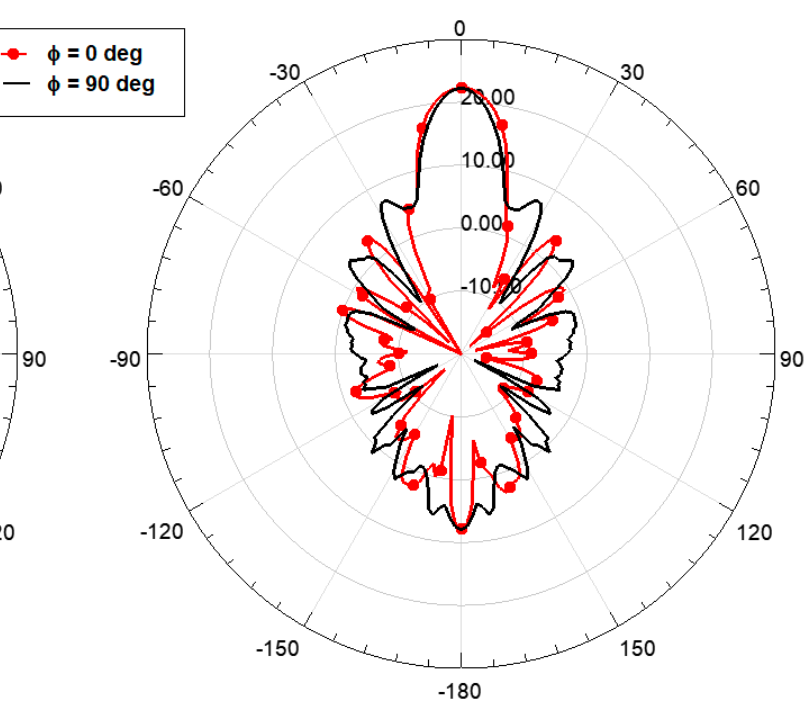

(b)

Figure 18. Simulated radiation patterns at $90 \mathrm{GHz}$ of the stand-alone horn antenna (a) and the horn with the opening of the blade in front $(\mathbf{b})$. Averaged $3 \mathrm{~dB}$ beam width is around $15^{\circ}$ (verified with measurements) in (a) and around $14^{\circ}$ in (b). Antenna gain is quite similar ( $21 \mathrm{dBi}$ and $22 \mathrm{dBi}$, respectively).

On the other hand, when the blade screens the horn, the power is mainly reflected by the horn antenna plus blade set. Those findings agree with the fact that when we placed the blade fixed in the open window position in between both horns, the variation of the losses could be neglected.

\subsubsection{Total Power Radiometer}

To perform the total power measurements, the quadratic-law diode detector HP8474E and the SR560 low noise video amplifier, configured with unity gain and a low pass filter with a cutoff frequency of $0.1 \mathrm{~Hz}$, were connected to the output of the IF amplifier. Detected voltage has been measured with a digital multimeter model 34401A (Keysight Technologies).

With the noise source in $\mathrm{ON}$ state, the transmitted noise power is modified by the attenuation provided by the variable attenuator. The noise source has an ENR around $15 \mathrm{~dB}$, and the attenuation is varied from $9 \mathrm{~dB}$ to $3.5 \mathrm{~dB}$. The detected voltage corresponds to a value proportional to the transmitted radiometric noise temperature $\left(T_{R}\right)$ plus the receiver noise temperature $\left(\mathrm{T}_{\text {sys }}\right)$.

$$
\mathrm{V}_{\mathrm{o}}=\mathrm{C}_{1} \mathrm{Gk}\left(\mathrm{T}_{\mathrm{R}}+\mathrm{T}_{\mathrm{sys}}\right) \mathrm{B}_{\mathrm{HF}}
$$

where $C_{1}$ is the response constant in $\mathrm{mV} / \mathrm{mW}, \mathrm{G}$ is the gain of the receiver, $\mathrm{k}$ the Boltzmann constant and $\mathrm{B}_{\mathrm{HF}}$ the effective noise bandwidth of the receiver. Without any attenuation, the maximum value of $T_{R}$ would be the hot temperature $\left(T_{\text {hot }}\right)$ of the noise source.

Figure 19 shows the voltage detected as a function of the equivalent temperature of noise transmitted with different positions of the attenuator. 


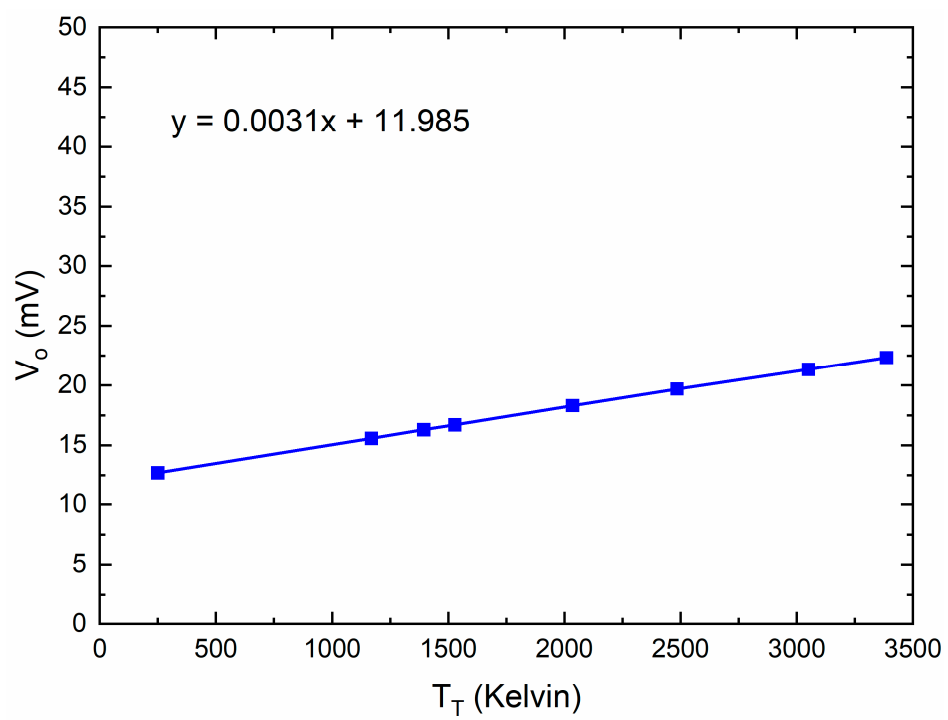

Figure 19. Voltage detected $V_{O}(m V)$ versus temperature $T_{T}(K)$ by the attenuated broadband noise source, for the measurement of the total power super-heterodyne radiometer.

From the measurement, we obtain the linear equation of voltage detected versus temperature (described in Figure 19 and Equation (9)), resulting in a response of $3.1 \mu \mathrm{V} / \mathrm{K}$, with an offset of $11.98 \mathrm{mV}$. This offset corresponds to the detected voltage proportional to the receiver noise temperature plus the temperature $T_{R}$ when it is equal to an ambient temperature of $290 \mathrm{~K}$.

\subsubsection{Dicke Radiometer}

As it was previously mentioned, measurements as a Dicke radiometer have been performed with an optical chopper model SR540 from Stanford Research Systems and a Lock-in Amplifier SR830, also from Stanford Research Systems. The scheme of the measurement system is shown in Figure 20.

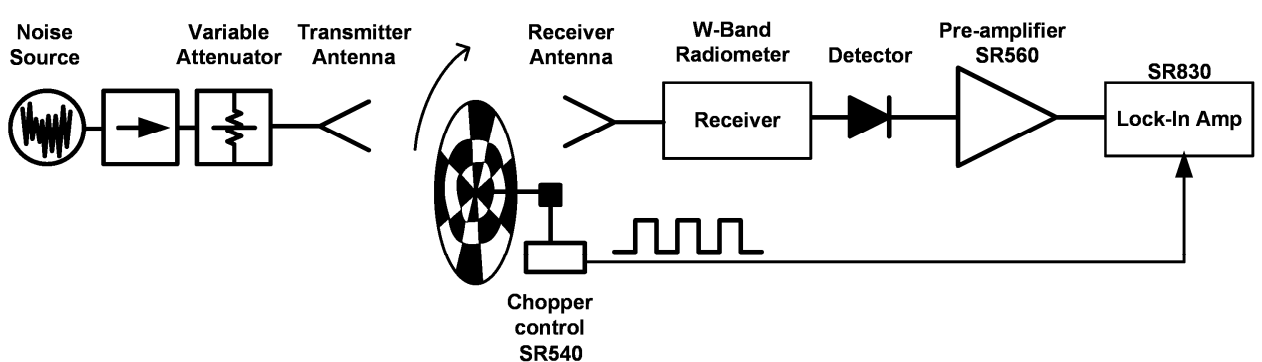

Figure 20. Diagram of the setup for measurement of Dicke radiometer in $\mathrm{W}$ band.

The optical chopper allows to modulate the incoming $\mathrm{W}$-band noise power into the receiver, with a square signal that is introduced in the lock-in amplifier as a reference signal, and which frequency can be fixed between $4 \mathrm{~Hz}$ and $3.7 \mathrm{kHz}$. The frequency of the modulating signal has been set to $120 \mathrm{~Hz}$ for these measurements.

The signal at the detector output is applied to the low noise preamplifier SR560 in DC coupling configuration with unity gain and its output is connected to the lock-in amplifier.

The signal detected in this configuration is a square signal, whose low level is proportional to a black body at room temperature $\left(\mathrm{T}_{\text {cold }}\right)$ plus the noise temperature added by the receiver $\left(\mathrm{T}_{\text {sys }}\right)$, measured when the optical chopper covers the transmitting antenna. 
Moreover, its high level is proportional to the noise temperature of the receiver plus the equivalent noise temperature of the transmitted noise power $\left(\mathrm{T}_{\text {hot }}\right)$.

$$
\begin{aligned}
& \mathrm{V}_{\mathrm{c}}=\mathrm{C}_{1} \mathrm{Gk}\left(\mathrm{T}_{\text {cold }}+\mathrm{T}_{\text {sys }}\right) \mathrm{B}_{\mathrm{HF}} \\
& \mathrm{V}_{\mathrm{h}}=\mathrm{C}_{1} \mathrm{Gk}\left(\mathrm{T}_{\text {hot }}+\mathrm{T}_{\text {sys }}\right) \mathrm{B}_{\mathrm{HF}}
\end{aligned}
$$

The lock-in amplifier performs a multiplication of the detected signal with the reference signal of the optical chopper plus a filtering that allows reducing the noise. In this filtering, a time constant in the range of $100 \mathrm{~ms}$ has been set, and the R parameter is measured. $\mathrm{R}$ parameter consists of an effective voltage proportional to the difference between the high and low levels of the signal detected according to (12).

$$
\mathrm{R}=\mathrm{C}_{2} \mathrm{G}\left(\mathrm{V}_{\mathrm{h}}-\mathrm{V}_{\mathrm{c}}\right)
$$

Figure 21 shows the parameter $\mathrm{R}$ in effective voltage as a function of the equivalent temperature of the noise power transmitted with different positions of the attenuator.

The linear equation relating effective voltage versus temperature is obtained, providing a measured response of $1.2 \mu \mathrm{Vrms} / \mathrm{K}$, with an offset of $-62.5 \mu \mathrm{Vrms}$.

\subsection{Direct Detection Radiometer}

The previously described measurement setups have been applied to the system shown in Figure 20. The RF chain is nominally the same, but without IF section, ended with the WR10 detector. The variable attenuator Hitachi W1513 has been also used to prevent the saturation of the amplifiers and the detector and to allow sweeping of input power (and, indirectly, Temperature $T_{R}$ ). Measurement setup was simplified as conversion is direct to DC without IF stage.

\subsubsection{Total Power Radiometer}

The setup for total power measurements of direct detection radiometer is shown in Figure 22.

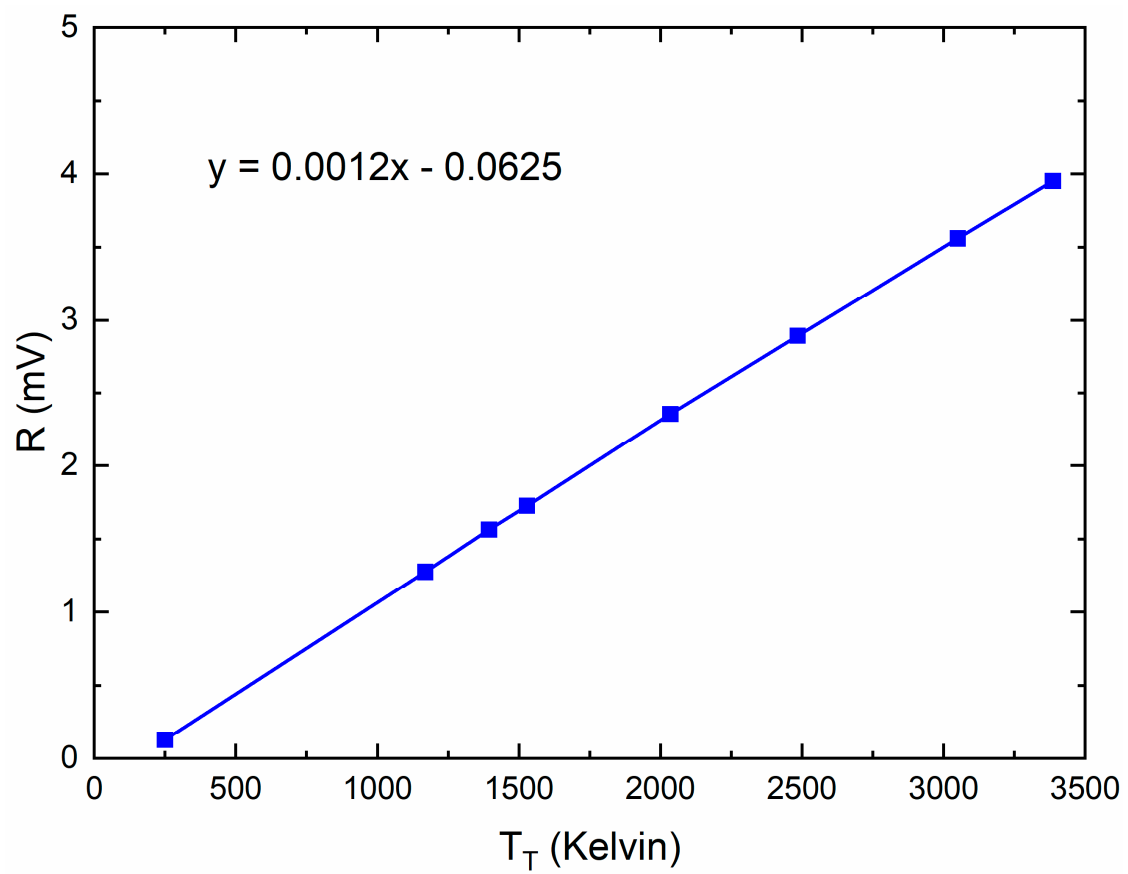

Figure 21. Parameter $\mathrm{R}$ in effective voltage ( $\mathrm{mVrms}$ ) versus the equivalent temperature of transmitted noise $\left(\mathrm{T}_{\mathrm{T}}(\mathrm{K})\right)$ by the source of attenuated broadband noise, for the measurement of the Dicke superheterodyne radiometer. 


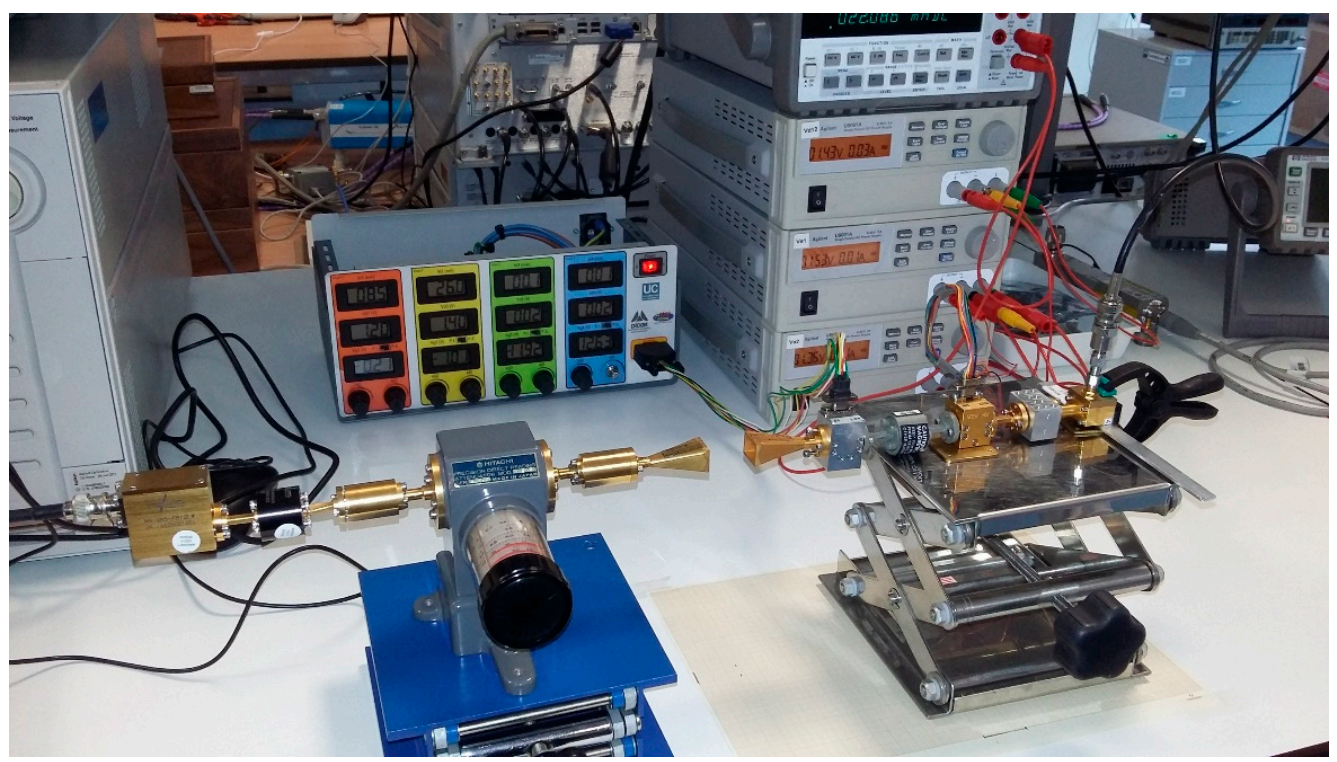

Figure 22. Photography of the setup for total power measurements of direct detection radiometer.

Sweeping the variable attenuator with the W-band noise source in ON mode, the detected values showed in Figure 23 were obtained. Responsivity $6 \times 10^{7} \mathrm{mV} / \mathrm{mW}$ is in the same order of magnitude, but slightly higher than expected from the simulations $\left(4 \times 10^{7} \mathrm{mV} / \mathrm{mW}\right)$ and an offset of $33.55 \mathrm{mV}$ was found.

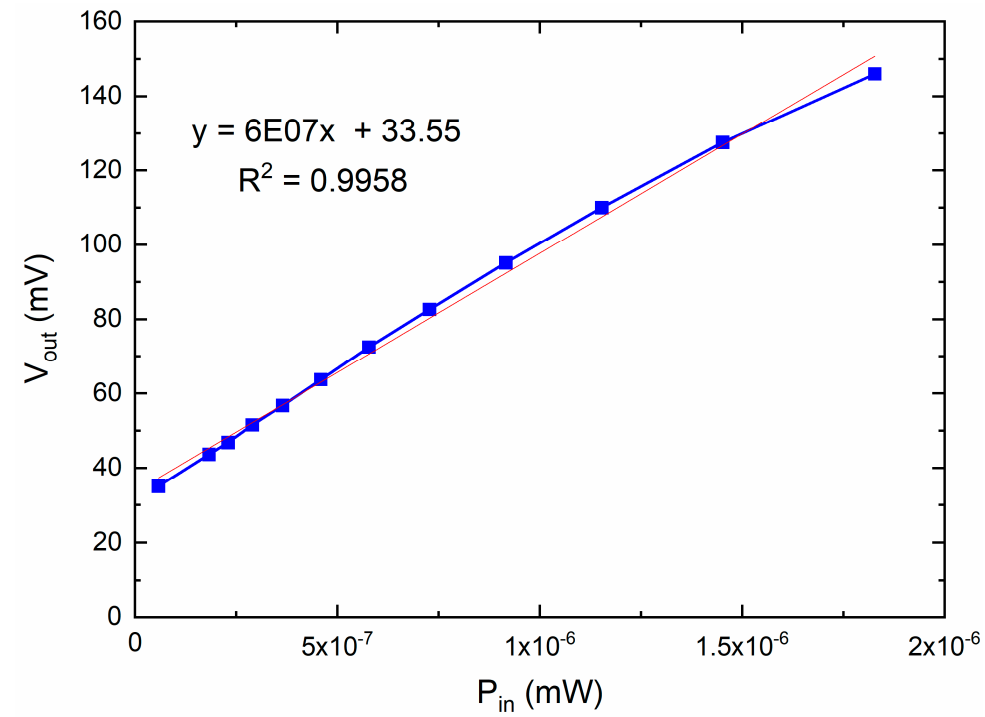

Figure 23. Voltage detected Vout $(\mathrm{mV})$ versus input power in $\mathrm{mW}$ when variable attenuator values were swept.

Assuming an estimated $\mathrm{B}_{\mathrm{HF}}$ of $20 \mathrm{GHz}$, input power was translated to temperature $\left(\mathrm{T}_{\mathrm{T}}\right)$ and Figure 23 was redrawn versus temperature (Figure 24) to obtain a responsivity of $15.7 \mu \mathrm{V} / \mathrm{K}$ (expected from simulations $11.8 \mu \mathrm{V} / \mathrm{K}$ ). 


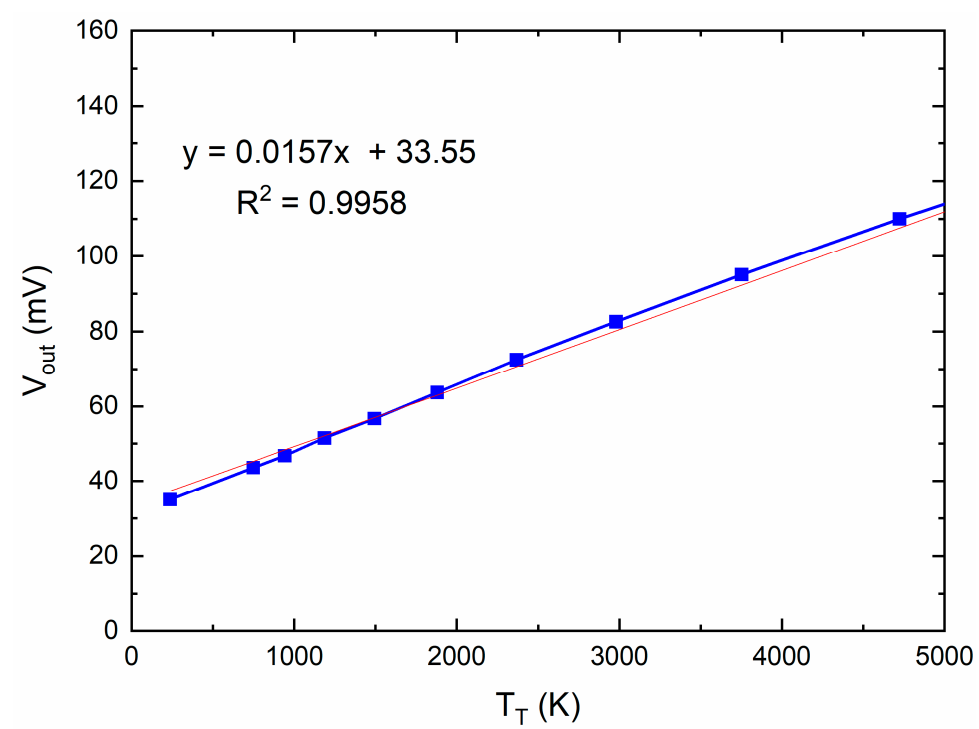

Figure 24. Voltage detected Vout $(\mathrm{mV})$ versus the equivalent temperature of transmitted noise $\left(\mathrm{T}_{\mathrm{T}}(\mathrm{K})\right)$ by the attenuated broadband noise source, for the measurement of the total power direct detection radiometer.

\subsubsection{Dicke Radiometer}

Setup described in Figure 20 (with the exception of the chopper which in this case was the model Thorlabs MC2000B), has been used with the receptor composed of the direct detection radiometer (Figure 25), obtaining the output waveforms shown in Figure 26. The $\mathrm{R}$ parameter (Equation (12)) (Figure 27) was obtained using a lock-in amplifier with a time constant in the range of $100 \mathrm{~ms}$. Notice that the waveform presents a more sinusoidal shape than the ideal simulated in Figure 13 due to the dynamic of coupling between horns with the rotating holes of the chopper in between and the oscilloscope input impedance. The measured slope of $\mathrm{R}$ plot versus Temperature $6 \mu \mathrm{V} / \mathrm{K}$ is quite similar to the expected from simulations $6.4 \mu \mathrm{V} / \mathrm{K}$ (Figure 14).

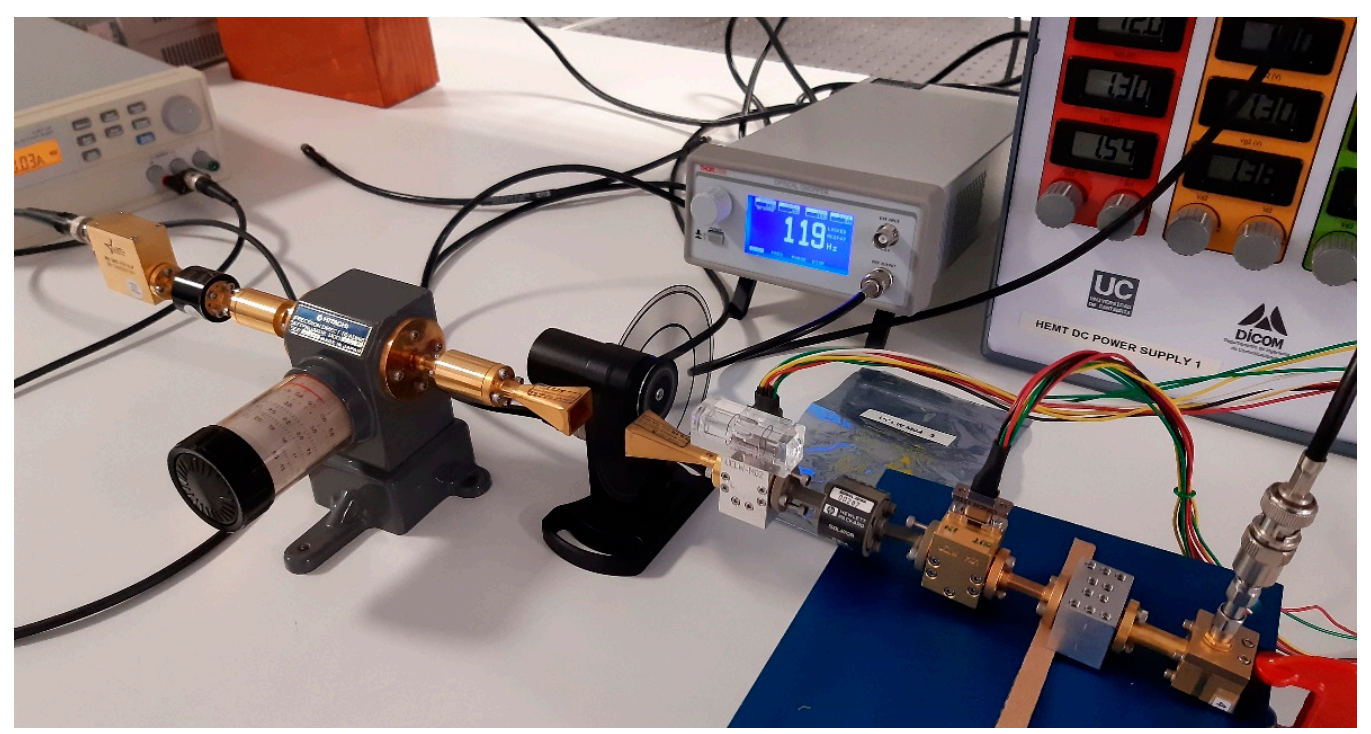

Figure 25. Photograph of the laboratory setup with the measurement system of the W-band direct detection radiometer in Dicke mode. Notice the rotating chopper in between the W-band horns. 


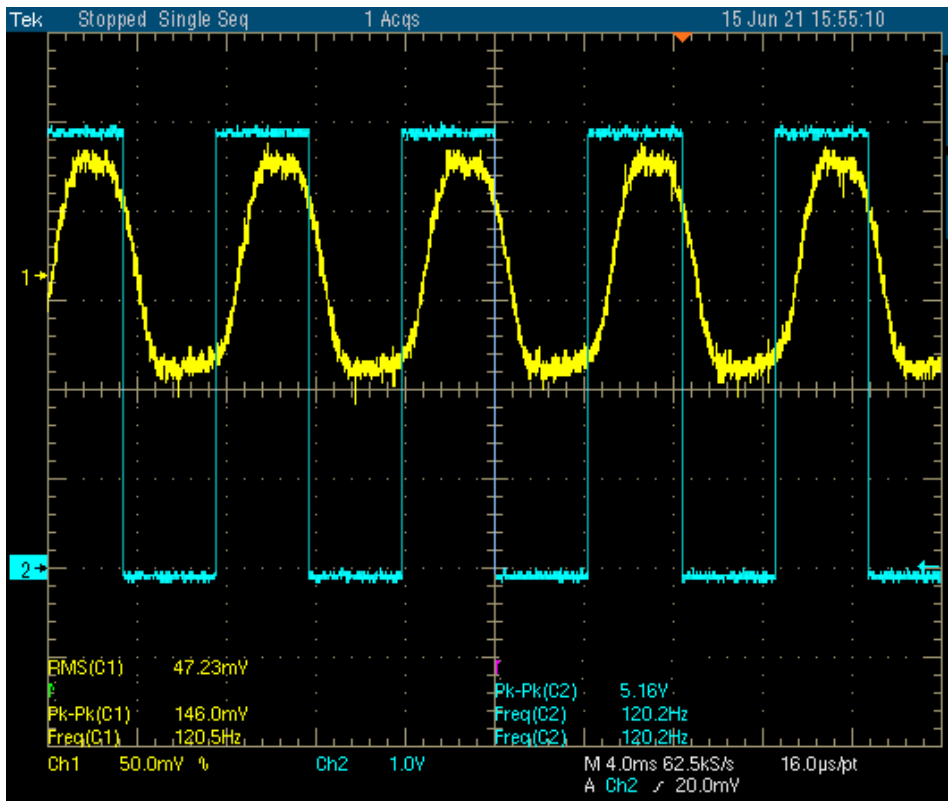

Figure 26. Output waveforms of the direct detection radiometer operating in Dicke mode at a modulating frequency of $120 \mathrm{~Hz}$. Square reference waveform from the chopper is superimposed. Capture corresponds to maximum power (minimum attenuation) from the noise source.

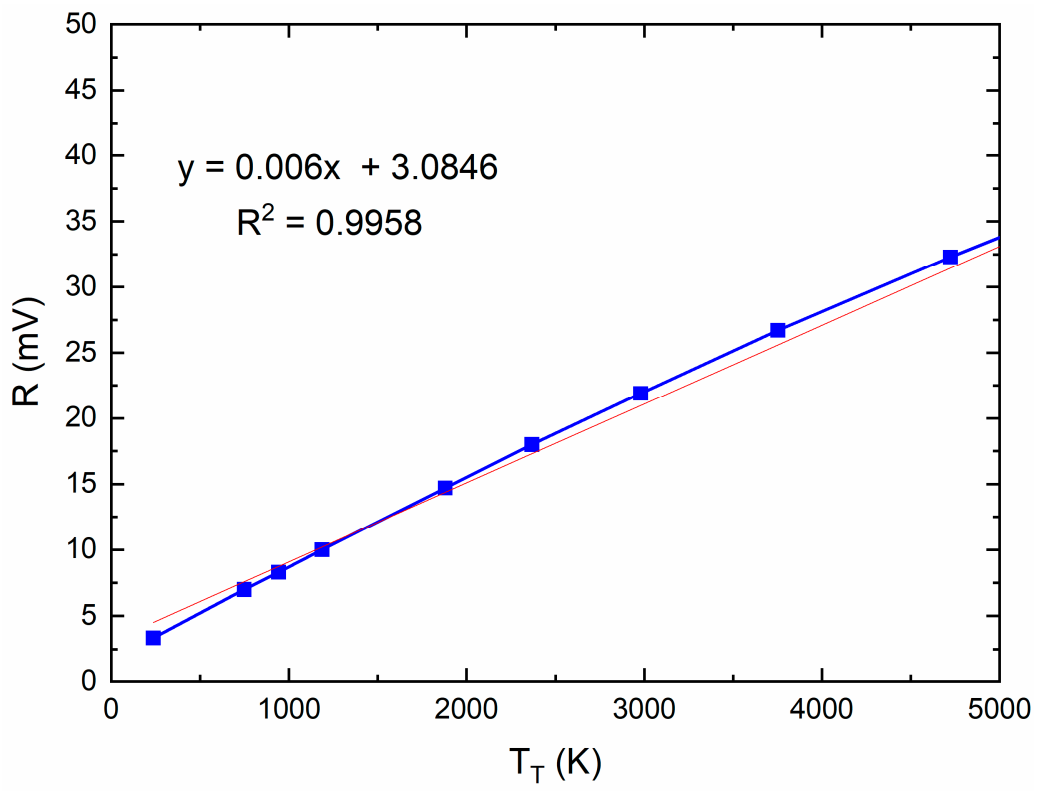

Figure 27. Parameter $\mathrm{R}$ in effective voltage ( $\mathrm{mVrms}$ ) versus the equivalent temperature of transmitted noise $\left(\mathrm{T}_{\mathrm{T}}(\mathrm{K})\right)$ by the source of attenuated broadband noise, for the measurement of the Dicke direct detection radiometer.

Table 4 summarizes the measured result of the four possible combinations. In general, the trends in the comparison between direct detection and super-heterodyne observed in the simulations (Tables 1 and 2) are maintained in the measurements. Comparing simulations and measurements, we can find the same order of magnitudes in R factor and even better performance measured than expected in total power responsivity. NEP is estimated from the minimum power and the effective bandwidth (Equation (7)). It is also possible to evaluate NEP from output low frequency spectrum [23], but we consider this method is prone to suffer higher uncertainty due to 1 / $\mathrm{f}$ noise and the determination of the low frequency bandwidths. In the case of sensitivities and NEP values estimated from 
measurements in a range $\sim 5 \mathrm{fW} / \operatorname{sqrt}(\mathrm{Hz})$ indicate the optimistic values obtained from simulations. In any case, values are in the order of other published data.

Table 4. Summary of results from the measurements.

\begin{tabular}{|c|c|c|c|c|c|c|c|}
\hline $\begin{array}{c}\text { Type of } \\
\text { Configuration } \backslash \text { Parameter }\end{array}$ & $\mathbf{B}_{\mathrm{HF}}(\mathrm{GHz})$ & $\begin{array}{c}\text { Total Power } \\
\text { Responsivity } \\
(\mathrm{mV} / \mathrm{mW})\end{array}$ & $\begin{array}{c}\text { Total Power } \\
\text { Responsivity } \\
(\mu \mathrm{V} / \mathrm{K})\end{array}$ & $\begin{array}{l}\text { Offset } \\
(\mathrm{mV})\end{array}$ & $\underset{(\mu \mathrm{Vrms} / \mathrm{K})}{\mathrm{R}}$ & $\begin{array}{c}\text { Sensitivity } \Delta T \\
(\mathrm{mK}) \\
(\tau=30 \mathrm{~ms})\end{array}$ & $\begin{array}{c}\text { NEP } \\
(\mathrm{pW} / \mathrm{sqrt}(\mathrm{Hz}))\end{array}$ \\
\hline Super-heterodyne total power & 10.7 & $1.18 \times 10^{7}$ & 3.1 & 11.98 & - & 152 & \multirow{2}{*}{0.0055} \\
\hline Super-heterodyne Dicke & 10.7 & & - & - & 1.2 & 305 & \\
\hline Direct detection total power & 19.9 & $6 \times 10^{7}$ & 15.7 & 33.55 & - & 58.49 & \multirow{2}{*}{0.0039} \\
\hline Direct detection Dicke & 19.9 & & - & - & 6 & 116.98 & \\
\hline
\end{tabular}

Some reported W-band and D-band radiometers [23,25-30] are listed in Table 5, which can be compared to the total power operation of the radiometers proposed in this work. When comparing sensitivity it must be taken into account that requirements for radio astronomy and imaging applications may be different, particularly about noise figures, and our proposal of radiometers comes from the first field. Advances in low-cost integration technologies like SiGe, BiCMOS and CMOS ([31-34]) may provide similar performance to modular designs based on GaAs or InP low noise technologies with reduced size and consumption (i.e., replacing chopper by on wafer switching or dual path LNAs). This could be suitable for imaging applications, but maybe it is not always convenient for radio astronomy applications. The integration of subsystems may include even the antenna, facilitating the implementation of radar-based active imaging systems with beamforming capabilities [35]. Even alternative detection procedures have been proposed using optical technology to provide images from $\mathrm{W}$-band radiation [36]. Another aspect is the distinction between radiometer system performance and stand-alone detector performance. Examples of detector performance can be found in [37].

Table 5. Summary of some reported results of $\mathrm{W}$ and $\mathrm{D}$ band radiometers.

\begin{tabular}{|c|c|c|c|c|c|}
\hline Ref $\backslash$ Parameter & $\begin{array}{c}B_{\mathrm{HF}}(\mathrm{GHz}) \text { and } \\
\text { (Frequency }(\mathrm{GHz}))\end{array}$ & $\begin{array}{l}\text { Responsivity } \\
(\mathrm{mV} / \mathrm{mW})\end{array}$ & $\begin{array}{l}\text { Sensitivity } \Delta T \\
\quad(m K)\end{array}$ & $\operatorname{NEP}(p W / s q r t(H z))$ & NF (dB) \\
\hline [23] & $20(83-103)$ & & 690 & & \\
\hline [23] & 15 (84-99) & $2.5 \times 10^{6}-5 \times 10^{6}$ & 830 & 0.021 & \\
\hline [25] & $4(89.5-93.5)$ & & 500 & & 11.5 \\
\hline [26] & $22(\mathrm{~W}$ band $)$ & 1000 & & 76 & \\
\hline [27] & 4 (W band) & & 550 & & 11.5 \\
\hline [28] & $12(\mathrm{~W}$ band $)$ & $16.10^{6}$ & 1000 & 0.009 & 8.9 \\
\hline [29] & $10(160-170)$ & $28 \times 10^{6}$ & $350(\tau=3.125 \mathrm{~ms})$ & $0.014 / 0.018$ & 8.14 \\
\hline [30] & $11.8(136)$ & $5.2 \times 10^{6}$ & $250(\tau=3.125 \mathrm{~ms})$ & 0.0014 & 7.9 \\
\hline [32] & 11.5 (centered 82.5) & - & 650 & 0.0093 & 6.4 \\
\hline [33] & centered 91 & - & 210 & - & 8.4 \\
\hline [34] & 10.7 (center 56) & $61 \times 10^{6}$ & & 0.0032 & 5.3 \\
\hline $\begin{array}{c}\text { This work } \\
\text { Super-heterodyne }\end{array}$ & 10.7 (W band) & $1.18 \times 10^{7}$ & 152 & 0.0055 & 4 \\
\hline $\begin{array}{c}\text { This work Direct } \\
\text { Detec }\end{array}$ & 19.9 (W band) & $6 \times 10^{7}$ & 58.49 & 0.0039 & 3.5 \\
\hline
\end{tabular}

\section{Conclusions}

Two W-band radiometers have been presented: a super-heterodyne configuration consisting of a pair of low noise amplifiers, a filter in W-band, a sub-harmonic mixer with intermediate frequency amplification, and, finally, detection through a quadratic-law diode detector, and a direct detection configuration replacing the IF section by W-band detection. Radiometers have been simulated (in the frequency domain for a total power mode and with transient enveloped for the Dicke mode) using the experimental characterization of the different individual subsystems, and then assembled and measured as complete systems. The radiometers operate mainly in the band from $80-$ to- $101 \mathrm{GHz}$ (defined by the 
RF BPF). Operation of both radiometers, super-heterodyne and direct detection, has been measured in two modes, as total power radiometers, and as a Dicke radiometers using an optical chopper to modulate the detected signal. In the super-heterodyne version, an $8 \mathrm{dBm}$ LO signal of frequency $27.1 \mathrm{GHz}$ is used, with an intermediate frequency from 0.1 to $\sim 15 \mathrm{GHz}$. It has performed a total gain, including conversion losses and IF amplification, around $50 \mathrm{~dB}$, a noise figure around $4 \mathrm{~dB}$, and an Effective Noise Bandwidth of $10 \mathrm{GHz}$. In the direct detection version, the RF front-end is the same, therefore the noise figure is similar, but responsivity was found to be slightly higher to the super-heterodyne version and the measured offset voltage was higher, as well as the noise effective bandwidth. There are no big differences in gain, as there are no conversion losses, neither IF section amplifier (in the super-heterodyne, IF gain compensates, more or less, conversion losses) but $\mathrm{W}$-band detector has higher sensitivity in a bandwidth beyond the fixed band of the BPF (80-to-101 GHz). Down conversion in the super-heterodyne version may contribute to a narrowing of the band. Effective Noise Bandwidth is wider in direct detection $(\sim 20 \mathrm{GHz})$ than in the super-heterodyne version, which increases the sensitivity, as is then verified by the fitted responsivity values. This conclusion is in agreement with the criteria explained by other authors $[23,24]$. Simulations predicted reasonably well the measured performance and the trends in the comparisons endorsing the simulation methodology. Nevertheless, this conclusion comes from a set of components that we could consider as typical taking into account that any down-conversion process will have a fixed If bandwidth, but we cannot exclude other conclusions for different components, particularly for different mixers and detectors. The comparison is mainly in terms of total power detection performance, but for other system specifications a super-heterodyne receiver may be required (those including spectrometers and filter banks, for example).

Considering other alternatives for radiometers, compared to modular GaAs or InP based, low cost integration technologies, such as BiCMOS or CMOS, may facilitate compact implementations of imaging systems with similar performances, but for specific applications interest remains, i.e., radio astronomy and cryogenic operation.

Author Contributions: Conceptualization, J.P.P. and B.A.; methodology, J.P.P. and B.A.; software, J.P.P. and B.A.; validation, J.P.P., B.A. and L.d.1.F.; formal analysis, B.A., L.d.1.F. and J.P.P.; investigation, E.V., J.V.T. and L.d.1.F.; resources, E.V., J.V.T. and L.d.1.F.; data curation, L.d.1.F., E.V., B.A. and J.P.P.; writing—original draft preparation, B.A., L.d.l.F., J.P.P. and E.V.; writing—review and editing, B.A., J.P.P. and E.V.; visualization, B.A. and L.d.l.F.; supervision, L.d.l.F. and E.A.; project administration, J.P.P., E.A. and L.d.1.F.; funding acquisition, J.P.P., L.d.l.F., B.A. and E.A. All authors have read and agreed to the published version of the manuscript.

Funding: This research was funded by the Spanish Ministry of Science and Innovation through the grant: PID2019-110610RB-C22 and by the Spanish Ministry of Economy and Competitiveness, Program CONSOLIDER-INGENIO reference CSD2010-00064, CONSOLIDER-SPATEK Network of Excellence and University of Cantabria, Industrial Doctorate reference 12.DI05.648.

Acknowledgments: The authors thank all the staff of the DICOM for their cooperation, and particularly to Eva Cuerno for the manufacture and assembly of the circuits.

Conflicts of Interest: The authors declare no conflict of interest. The funders had no role in the design of the study; in the collection, analyses, or interpretation of data; in the writing of the manuscript, or in the decision to publish the results.

\section{References}

1. Pospieszalski, M.W.; Wollack, E.J.; Bailey, N.; Thacker, D.; Webber, J.; Nguyen, L.D.; Le, N.; Lui, M. Design and Performance of Wideband, Low-Noise, Millimeter-Wave Amplifiers for Microwave Anisotropy Probe Radiometers. In Proceedings of the 2000 IEEE MTT-S International Microwave Symposium Digest (Cat. No.00CH37017), Boston, MA, USA, 11-16 June 2000; pp. 217-220.

2. Lamarre, J.M.; Puget, J.L.; Bouchet, F.; Ade, P.A.; Benoit, A.; Bernard, J.P.; Bock, J.; De Bernardis, P.; Charra, J.; Couchot, F.; et al. The Planck High Frequency Instrument, a third generation CMB experiment, and a full sky submillime-ter survey. New Astron. Rev. 2003, 47, 1017-1024. [CrossRef]

3. Prisner, T.F.; van der Est, A.; Bittl, R.; Lubitz, W.; Stehlik, D.; Möbius, K. Time-resolved W-band (95 GHz) EPR spectroscopy of Zn-substituted reaction centers of Rhodobacter sphaeroides R-26. Chem. Phys. 1995, 194, 361-370. [CrossRef] 
4. Yujiri, L.; Shoucri, M.; Moffa, P. Passive millimeter wave imaging. IEEE Microw. Mag. 2003, 4, 39-50. [CrossRef]

5. Shoucri, M.; Davidheiser, R.; Hauss, B.; Lee, P.; Mussetto, M.; Young, S.; Yujiri, L. A passive millimeter wave camera for landing in low visibility conditions. In Proceedings of the AIAA/IEEE Digital Avionics Systems Conference, 13th DASC, Phoenix, AZ, USA, 30 October-3 November 1994.

6. Del Torto, F.; Bersanelli, M.; Cavaliere, F.; De Rosa, A.; D'Arcangelo, O.; Franceschet, C.; Gervasi, M.; Mennella, A.; Pagana, E.; Simonetto, A.; et al. W-band prototype of platelet feed-horn array for CMB polarisation measurements. J. Instrum. 2011, 6, P06009. [CrossRef]

7. Kraus, J.D. Radio Astronomy, 2nd ed.; Cygnus-Quasar Books: Powell, OH, USA, 1986.

8. Tiuri, M. Radio astronomy receivers. IRE Trans. Antennas Propag. 1964, 12, 930-938. [CrossRef]

9. Ulaby, F.T.; Moore, R.K.; Fung, A.K. Microwave Remote Sensing—Active and Passive; Artech House Inc.: Norwood, MA, USA, 1981; Volume I.

10. Dicke, R.H. The measurements of thermal radiation at microwave frequencies. Rev. Sci. Instrum. 1946, 17, 268-275. [CrossRef] [PubMed]

11. Goldstein, S. A Comparison of Two Radiometer Circuits. Proc. IRE 1955, 43, 1663-1666. [CrossRef]

12. Aja, B.; Artal, E.; De La Fuente, L.; Pascual, J.; Mediavilla, A.; Roddis, N.; Kettle, D.; Winder, W.; Cara, L.; De Paco, P. Very low-noise differential radiometer at $30 \mathrm{GHz}$ for the PLANCK LFI. IEEE Trans. Microw. Theory Tech. 2005, 53, 2050-2062. [CrossRef]

13. Cano, J.L.; Villa, E.; Teran, V.; Gonzalez, E.; De La Fuente, L.; Artal, E.; Mediavilla, A. A W-band polarimeter for radio astronomy applications: Design and simulation. In Proceedings of the 2015 International Conference on Electromagnetics in Advanced Applications (ICEAA), Turin, Italy, 7-11 September 2015; pp. 452-455.

14. Bischoff, C.; Brizius, A.; Buder, I.; Chinone, Y.; Cleary, K.; Dumoulin, R.N.; Kusaka, A.; Monsalve, R.; Næss, S.; Newburgh, L.B.; et al. THE Q/U IMAGING EXPERIMENT INSTRUMENT. Astrophys. J. 2013, 768, 9. [CrossRef]

15. Gutiérrez, J.; Pascual, J.P.; Tazón, A. Merged simulation procedure for W-band imaging systems. Int. J. RF Microw. Comput. Eng. 2018, 28, e21284. [CrossRef]

16. Doo, J.; Park, W.; Choe, W.; Jeong, J. Design of Broadband W-Band Waveguide Package and Application to Low Noise Amplifier Module. Electronics 2019, 8, 523. [CrossRef]

17. Ustundag, B.; Turkmen, E.; Cetindogan, B.; Guner, A.; Kaynak, M.; Gurbuz, Y. Low-Noise Amplifiers for W-Band and D-Band Passive Imaging Systems in SiGe BiCMOS Technology. In Proceedings of the 2018 Asia-Pacific Microwave Conference (APMC), Kyoto, Japan, 6-9 November 2018; pp. 651-653.

18. Lardizabal, S.; Hwang, K.C.; Kotce, J.; Brown, A.; Fung, A. Wideband W-Band GAN LNA MMIC with State-of-the-Art Noise Figure. In Proceedings of the 2016 IEEE Compound Semiconductor Integrated Circuit Symposium (CSICS), Austin, TX, USA, 23-26 October 2016; pp. 1-4.

19. Terán Collantes, J.V. Low Noise Receivers for Millimetre-Wave Bands Radio Astronomy. Ph.D. Thesis, University of Cantabria, 2017. Available online: https:/ / repositorio.unican.es/xmlui/handle/10902/11503 (accessed on 19 September 2021).

20. Advanced Design System (ADS). Available online: https://www.keysight.com/es/en/products/software/pathwave-designsoftware/pathwave-advanced-design-system.html (accessed on 8 July 2021).

21. Aja, B.; Pascual, J.P.; De La Fuente, L.; Gallegos, J.; Artal, E. A New Method to Obtain Total Power Receiver Equivalent Noise Temperature. In Proceedings of the 33rd European Microwave Conference, Munich, Germany, 2-10 October 2003 ; pp. 355-358.

22. Pascual, J.P.; Aja, B.; De La Fuente, M.L.; Pomposo, T.; Artal, E. System Simulation of a Differential Radiometer Using Standard RF-Microwave Simulators. Simulation 2005, 81, 735-755. [CrossRef]

23. May, J.W.; Rebeiz, G.M. Design and Characterization of W-Band SiGe RFICs for Passive Millimeter-Wave Imaging. IEEE Trans. Microw. Theory Tech. 2010, 58, 1420-1430. [CrossRef]

24. Weissbrodt, E.; Kallfass, I.; Hulsmann, A.; Tessmann, A.; Leuther, A.; Massler, H.; Ambacher, O. W-band radiometer system with switching front-end for multi-load calibration. In Proceedings of the 2011 IEEE International Geoscience and Remote Sensing Symposium, Vancouver, BC, Canada, 24-29 July 2011; pp. 3843-3846.

25. Quan, L.; Yong-Hong, Z.; Qi-Ke, C.; Yong, F.; Jian-Yu, Y.; Liang-Chao, L. The W Band Radiometer for Imaging. In Proceedings of the 2007 International Conference on Communications, Circuits and Systems, Kokura, Japan, 11-13 July 2007; pp. $1306-1308$.

26. Xie, L.; Zhang, H.; Fan, Y. W-Band Radiometer Front End Module for Real-Time Imaging. Microw. J. 2014, 57, 80-90.

27. Li, L.C.; Yang, J.Y.; Xiong, J.T.; Wu, J.J.; Jiang, Z.M.; Zheng, X. W Band Dicke-Radiometer for Imaging. Int. J. Infrared Millim. Waves 2008, 29, 879-888. [CrossRef]

28. Zhou, L.; Wang, C.-C.; Chen, Z.; Heydari, P. A W-band CMOS Receiver Chipset for Millimeter-Wave Radiometer Systems. IEEE J. Solid-State Circuits 2011, 46, 378-391. [CrossRef]

29. Dacquay, E.; Tomkins, A.; Yau, K.H.K.; Laskin, E.; Chevalier, P.; Chantre, A.; Sautreuil, B.; Voinigescu, S.P. D-Band Total Power Radiometer Performance Optimization in an SiGe HBT Technology. IEEE Trans. Microw. Theory Tech. 2012, 60, 813-826. [CrossRef]

30. Kanar, T.; Rebeiz, G.M. A low-power SiGe D-band total power radiometer with NEPmin of $1.4 \mathrm{fW} / \mathrm{Hz} \frac{1}{2}$ and NETD of $0.25 \mathrm{~K}$. In Proceedings of the 2016 IEEE MTT-S International Microwave Symposium (IMS), San Francisco, CA, USA, 22-27 May 2016; pp. $1-4$.

31. Frounchi, M.; Alizadeh, A.; Ying, H.; Coen, C.T.; Gasiewski, A.J.; Cressler, J.D. Millimeter-Wave SiGe Radiometer Front End With Transformer-Based Dicke Switch and On-Chip Calibration Noise Source. IEEE J. Solid-State Circuits 2021, 56, 1464-1474. [CrossRef] 
32. Feng, G.; Yi, X.; Meng, F.; Boon, C.C. A W-Band Switch-Less Dicke Receiver for Millimeter-Wave Imaging in 65 nm CMOS. IEEE Access 2018, 6, 39233-39240. [CrossRef]

33. Bi, X.; Arasu, M.A.; Zhu, Y.; Je, M. A Low Switching-Loss W-Band Radiometer Utilizing a Single-Pole-Double-Throw Distributed Amplifier in 0.13-um SiGe BiCMOS. IEEE Trans. Microw. Theory Tech. 2016, 64, 226-238. [CrossRef]

34. Malotaux, S.; Babaie, M.; Spirito, M. A Total-Power Radiometer Front End in a 0.25-um BiCMOS Technology with Low 1/f -Corner. IEEE J. Solid-State Circuits 2017, 52, 2256-2266. [CrossRef]

35. Peng, P.; Chen, P.; Kao, C.; Chen, Y.; Lee, J. A 94 GHz 3D Image Radar Engine With 4TX/4RX Beamforming Scan Tech-nique in 65 nm CMOS Technology. IEEE J. Solid-State Circuits 2015, 50, 656-668. [CrossRef]

36. Zhang, Y.; Martin, R.D.; Shi, S.; Wright, A.A.; Yao, P.; Shreve, K.; Mackrides, D.; Harrity, C.; Prather, D.W. 95-GHz Front-End Receiving Multichip Module on Multilayer LCP Substrate for Passive Millimeter-Wave Imaging. IEEE Trans. Compon. Packag. Manuf. Technol. 2018, 8, 2180-2189. [CrossRef]

37. Gutiérrez, J.; Zeljami, K.; Pascual, J.P.; Fernández, T.; Tazón, A. Comparison of Microstrip W-Band Detectors Based on Zero Bias Schottky-Diodes. Electronics 2019, 8, 1450. [CrossRef] 